\title{
SOBRE LA ADMISIBILIDAD DE PRUEBAS ILEGALES EN EL DERECHO INTERNACIONAL: UNA VISIÓN SISTEMÁTICA*1
}

\author{
Amparo Estefanía Palomino Doza*2 / Juliana Camacho Martínez*3 \\ Iván Alejandro Restrepo Pardo *4 / Jorge Mario Rodríguez Ramírez"5 \\ Javier Antonio Silva Monroy"*6 / Nicolás Iván González Guevara*7 \\ Edgar Oswaldo Acero Quemba*8 / Luis Carlos Roncancio Martínez*9 \\ Nicole Ríos Martínez $z^{* 10}$
}

\section{ReSUMEN:}

En el Sistema de Derecho Internacional no existen métodos suficientemente coercitivos para asegurar la obtención y producción de una prueba, lo cual origina que en muchas controversias internacionales tales fenómenos puedan darse de forma unilateral y en algunos casos, ilegalmente. Así las cosas, el objetivo de este texto es demostrar que en el Derecho Procesal Internacional existen vacíos conceptuales en lo relacionado con el aporte de las pruebas ilegalmente obtenidas. Para sustentar lo anterior, abordaremos un estudio de las principales cortes permanentes y de aquellos tribunales $\mathrm{Ad} \mathrm{Hoc} \mathrm{crea-}$ dos para juzgar casos de violaciones de Derechos Humanos o de Derecho Internacional Humanitario. Presentaremos un análisis desarrollado desde la perspectiva de la Teoría de Sistemas Sociales, la cual resulta útil para enten-

*1 Artículo basado en la ponencia ganadora del XII Concurso Internacional para Estudiantes de Derecho Nivel Pregrado del Instituto Colombiano de Derecho Procesal. Bogotá-Colombia (2011).

*2 Abogada de la Universidad de los Andes. Visitante profesional de la Corte Interamericana de Derechos Humanos (mayo-diciembre de 2012). Ha sido Abogada asociada de Brigard \& Urrutia Abogados y Profesora asistente de la Facultad de Derecho, Universidad de los Andes.

*3 Estudiante de quinto semestre de la Universidad de los Andes. Monitora del curso Hermenéutica Jurídica con el profesor Pablo Cárdenas Rey durante el primer semestre del 2011 y del curso Obligaciones I del mismo profesor durante el primer semestre del año en curso.

*4 Estudiante de noveno semestre de Derecho de la Universidad de los Andes. Miembro activo del Consultorio Jurídico. 
der cómo las cortes internacionales admiten o inadmiten aquella evidencia obtenida de forma irregular, en desarrollo de su auto-legitimación y de sus estructuras lógicas de control de comunicaciones.

Palabras clave: Teoría de Sistemas Sociales, evidencia obtenida ilegalmente, Cortes y tribunales internacionales, sistema jurídico internacional.

\begin{abstract}
In the system of international law there are no strongly coactive methods to ensure the collection and production of evidence, which causes than in many international disputes such phenomena can occur unilaterally and in some cases, illegally. So, the objective of this paper is to show that in the Procedural International Law conceptual gaps exist regarding the supply of illegally obtained evidence. To support this, we will study the main permanent courts and $A d H o c$ tribunals or established to judge cases of Human Rights violations and International Humanitarian Law. We will present an analysis developed from the perspective of the social systems theory, which is useful for understanding how international courts admit or exclude that evidence illegally obtained, therefore developing their self-legitimization and their logical structures of communication control.
\end{abstract}

Key Words: Social systems theory, illegally obtained evidence, international courts and tribunals, international legal system.

Abogado de la Universidad de los Andes. Coordinador de la Especialización en Legislación Financiera de la Universidad de los Andes, Abogado Dirección Jurídica Asociación Gremial de Comisionistas de Bolsa (Asobolsa).

*6 Javier Antonio Silva Monroy. Abogado Universidad de los Andes. Auxiliar judicial ad honorem en el despacho del presidente de la Corte Constitucional Jorge Iván Palacio Palacio (Octubre 2012- abril 2013). Becario del programa "Quiero estudiar" de la Universidad de los Andes (2007).

*7 Estudiante de Décimo Semestre de la Universidad de los Andes. Asistente Jurídico de Tejeiro Abogados desde Marzo de 2012.

*8 Edgar Oswaldo Acero Quemba. Estudiante de noveno semestre de derecho de la Universidad de los Andes. Opción en Escuela de gobierno Carlos Lleras Restrepo y Administración de Empresas de la Universidad de los Andes, monitor del Curso Historia del Desarrollo Empresarial Colombiano a cargo del profesor Luis Fernando Molina durante el primer semestre del 2012.

*9 Luis Carlos Roncancio Martínez. Estudiante de noveno semestre de Derecho de la Universidad de los andes. Miembro activo del Consultorio jurídico de la Universidad de los Andes.

*10 Abogada de la Universidad de los Andes. Actualmente trabaja en el Área de aduanas y comercio exterior y en el Área de cambios e inversiones internacionales de la firma Ernst \& Young. Fue pasante para la implementación del Tratado de Libre Comercio suscrito por Colombia con Estados Unidos en la Oficina de Asuntos Legales Internacionales del Ministerio de Comercio, Industria y Turismo. También fue miembro activo del programa Justicia Global y Derechos Humanos de la Universidad de los Andes.

Con especial afecto, agradecemos a los doctores Horacio Cruz Tejada, Director del Área de Derecho Procesal de la Universidad de los Andes y Tania Luna Blanco, Ex Directora del Área de Derecho Público del Consultorio Jurídico de la Universidad de los Andes, sin cuyo apoyo y crítica esta investigación no hubiera salido adelante. 


\section{INTRODUCCIÓN}

En el Sistema de Derecho Internacional, a diferencia de algunos sistemas jurídicos domésticos, no existen métodos concretos para asegurar la obtención y producción de una prueba ${ }^{1}$. Aunque un Estado demandante presente toda la evidencia pertinente y conducente para la consecución de un fallo, si ésta se encuentra bajo el dominio del demandado, ni el Estado solicitante ni el juez podrán ejercer coerción para obtenerlas ${ }^{2}$. Por esta razón, en muchas controversias internacionales la obtención de la prueba puede darse de manera unilateral y en algunos casos, de forma ilegal. Ahora bien, el análisis de admisibilidad de una prueba ilegalmente obtenida se encuentra en una etapa procesal previa a la etapa de la valoración conjunta de las pruebas.

El concepto de la legalidad o licitud de los medios de obtención de la prueba en el Sistema Jurídico Internacional, se encuentra determinado por criterios generales como la justicia o la equidad. Los jueces de las cortes y tribunales internacionales no distinguen entre la prueba ilícitamente obtenida y aquella afectada por ilegalidad, hecho que justifica que en adelante, ambos términos sean tratados indistintamente para efectos del presente texto. Además, en el Derecho Internacional no se le ha otorgado un trato diferente a las pruebas obtenidas bajo violación de normas de Ius Cogens de a aquellas que violan normas de menor categoría ${ }^{3}$. Valga aclarar que, a pesar de existir en Derecho Internacional una sanción de nulidad aplicable a los tratados contrarios a normas Ius Cogens ${ }^{4}$, no es claro cómo la misma aplicaría a dilemas estrictamente probatorios.

Así las cosas, el objetivo de este texto es demostrar que en el Derecho Procesal Internacional existen vacíos conceptuales en lo relacionado con la admisibilidad de las pruebas ilegalmente obtenidas en los casos objeto de litigio. Para sustentar lo anterior, abordaremos un estudio de las principales cortes permanentes y de aquellos tribunales $\mathrm{Ad} \mathrm{Hoc} \mathrm{o} \mathrm{creados} \mathrm{para} \mathrm{juzgar} \mathrm{casos} \mathrm{concretos} \mathrm{de} \mathrm{violaciones} \mathrm{de} \mathrm{Derechos}$ Humanos o de Derecho Internacional Humanitario, puesto que todos estos son parte integrante de lo que denominaremos el Sistema de Derecho Internacional. La importancia de ahondar en temas como el que aquí se propone, yace en los pasos que el Sistema está dando para implementar una justicia global.

REISMAN, W, Michael; FREEDMAN, Eric E. “The plaintiff's Dilemma: Illegally Obtained Evidence and Admissibility in International Adjudication", Yale Law School Legal Scholarship Series. 76 Am. J. Int'l L. 737. 1982. En: http://heinonline.org/. Consultado el 10/02/2013. p. 738.

$2 \quad$ Ibídem. p. 738.

3 CHINKIN, C.M. "The Challenge of Soft law: Development and change in International Law", International and Comparative Law Quarterly. Volumen 38. 1989. Londres. British Institute of International and Comparative Law. Pp. 850-866.

4 Convención de Viena sobre el Derecho de los Tratados. UN Doc. A/Conf.39/27; 1155 UNTS 331; 8 ILM 679 (1969); 63 AJIL 875 (1969). Artículo 64. 
Presentaremos un análisis desarrollado desde la perspectiva de la Teoría de Sistemas Sociales ${ }^{5}$, la cual resulta útil para entender el derecho probatorio a nivel internacional como una estructura lógica y teleológica. Todo ello conducirá a demostrar que el tema de admisión de la prueba no sólo responde a una lógica de derecho procesal, sino que también se justifica en los fines que detenta la comunidad internacional en general.

Para tal efecto, el presente trabajo se estructura así: En primer lugar, esbozaremos de manera general los postulados de la Teoría de Sistemas Sociales y cómo estos son útiles para entender el funcionamiento y el fin del Derecho Internacional. En un segundo plano, abordaremos el concepto de prueba ilícita en el Derecho Internacional y su distinción con el sistema doméstico colombiano, con el fin de evidenciar los aportes que puede recibir el Sistema Jurídico Internacional de otros sistemas jurídicos. Acto seguido, mencionaremos las principales reglas de exclusión vinculantes para los operadores jurídicos en el Derecho Internacional y las excepciones a las reglas que exigen la inadmisibilidad de ciertas pruebas. En cuarto orden, expondremos las reglas de exclusión de cada corte o tribunal internacional, incluyendo aquellas que se encuentran explícitas en sus estatutos o que se derivan de sus prácticas. Por último, presentaremos algunas conclusiones haciendo además alusión especial a un caso que fue objeto de duros cuestionamientos: la decisión inhibitoria proferida por la Sala de Casación Penal de la Corte Suprema de Justicia colombiana el 18 de mayo de 2011, a favor del ex Representante a la Cámara Wilson Borja, mediante la cual se declaró la ilegalidad de las pruebas electrónicas halladas en la operación Fénix, en la cual se dio muerte al jefe guerrillero alias "Raúl Reyes".

\section{La Teoría de Sistemas Sociales y Su Relación CON EL DERECHO}

La Teoría de Sistema Sociales fue introducida en 1984 por el sociólogo alemán Niklas Luhmann en su texto Soziale Systeme: Grundri einer allgemeinen. Esta propuesta explica la forma en la que coexisten y actúan entre sí y en su interior los sistemas sociales. Ahora bien, ¿qué se entiende por sistemas sociales? Un sistema social es un conjunto de elementos relacionados entre sí, a través de un lenguaje propio, dirigidos a cumplir un fin social. Esta idea se presenta como adecuada para explicar la relación entre las reglas de admisibilidad de pruebas ilegalmente obtenidas en el Derecho Internacional y entender así, el derecho probatorio a nivel internacional como una estructura coherente, con una arquitectura y matriz propias. En el

La Teoría de Sistema Sociales intenta explicar la co-existencia de los sistemas políticos, económicos y de Derecho, entre otros, y cómo estos actúan entre si y su interior. Esta teoría fue desarrollada inicialmente por el sociólogo Alemán Niklas Luhmann en el texto "Soziale Systeme: Grundri einer allgemeinen". 1984. 
sistema se pueden apreciar las fronteras, dentro de las cuales los adjudicadores ${ }^{6} \mathrm{y}$ las partes pasan a ser operadores y las sentencias son actos de legitimación. Desde dicha perspectiva, los principios son comunicaciones propias del sistema que guían las actuaciones de sus operadores y las normas son desarrollo de los mismos.

Para adoptar esta óptica, se deben dejar por sentado conceptos básicos de la teoría como son la autopoiesis, la diferenciación, la comunicación y el control, los operadores del sistema y las estructuras de legitimación. Una referencia específica a cada uno de ellos se presenta a continuación en tres secciones: Teoría de la comunicación, teoría de la diferenciación y teoría de la evolución del sistema ${ }^{7}$. El propósito que se tiene al dilucidar estas primeras cuestiones de la Teoría de Sistemas Sociales, está en que el lector ajeno al tema comprenda cómo el presente trabajo concibe, de manera muy específica, el Sistema Jurídico Internacional como un sistema de comunicaciones sociales.

\section{i. La teoría de la comunicación}

Como ya expresamos anteriormente, el Sistema debe entenderse como un conjunto de elementos que gozan de un lenguaje propio y que se dirigen hacia un mismo objetivo. Así, se puede decir que el Sistema jurídico funciona como un instrumento para comunicar control ${ }^{8}$, con lo que se introduce el concepto de la comunicación como elemento central en la Teoría de Sistemas Sociales. Comunicación es la manifestación de los fines del sistema que se expresan a través de los fenómenos de causa y efecto. Una causa no puede tener un efecto si no existe una comunicación entre los mismos ${ }^{9}$. La comunicación es entonces el medio a través del cual se transfiere la información en el Sistema ${ }^{10}$. Para el caso del Sistema Jurídico Internacional, una

$6 \quad$ Al respecto, es importante señalar que en el Derecho Internacional no se puede hablar genéricamente de la figura del juez. En algunos casos como en la Corte Interamericana de Derechos Humanos, Corte Internacional de Justicia, la Corte Penal Internacional, entre otros, existe la figura de un juez en virtud de los estatutos que dan vida al tribunal. En otros casos, como en el Sistema de Solución de Controversias de la Organización Mundial del Comercio o la mayoría de tribunales ad hoc como el ICSID, no se habla de jueces sino de paneles o de árbitros, según corresponda. Cuando se refiere a la figura del juez, de forma genérica en el Sistema Internacional, se habla de "international adjudicator, prosecutor" o incluso de "decision makers". Por esta razón, en aras de mantener una lógica con la doctrina internacional, se ha adoptado el término "adjudicador" para hacer alusión a las distintas formas que adopta el fallador en el litigo internacional.

7 BLECKMANN, Frank. "Derecho penal y teoría de sistemas". En: GÓMEZ JARA Diez, Carlos (coordinador). Teoría de sistemas y derecho penal. Fundamentos y posibilidades de aplicación. Primera edición. Bogotá. Universidad Externado de Colombia. 2009. p. 21.

8 Ibídem.

$9 \quad$ Ibídem. p. 20.

10 La información hace referencia al mensaje enviado por el Sistema a los sujetos que reconoce para que se dé el efecto deseado. 
comunicación puede ser un acto como una sentencia de primera instancia de un tribunal, una conducta violatoria del Derecho Internacional Humanitario por parte de un agente del Estado e incluso un tratado internacional ratificado por diferentes naciones. Estos "actos" dentro de la teoría son denominados "comunicaciones", dado que su ocurrencia crea efectos dentro del Sistema Jurídico Internacional. De esta forma, una sentencia de primera instancia proferida por un tribunal internacional, es un acto jurídico procesal que decide un pleito entre partes; una conducta violatoria del Derecho Internacional Humanitario por parte de un agente del Estado, es una situación fáctica que le genera una responsabilidad jurídica al mismo; y un tratado internacional ratificado por diferentes naciones, es una acto jurídico que crea derechos y obligaciones.

Ahora bien, si un sistema es una herramienta para generar control, en una Teoría de Sistemas Sociales la comunicación es sólo una parte de la explicación. El control consiste en instituir una consecuencia jurídica para asegurar la comunicación, esto es, que la norma establecida por el sistema sea cumplida por la sociedad, lo cual implica en últimas reducir los grados de libertad que tiene un sujeto para decidir ${ }^{11}$. El Sistema no puede asegurar que siempre se cumplirán las normas, pero lo que sí garantiza es que cuando el fin de una norma es incumplido, se considerará que dicha violación es suficiente para que él mismo produzca una comunicación que asegure el fin normativo, es decir, él generará una sanción o pena para asegurar la legitimación de la disposición infringida. Con la aplicación reiterada de sanciones se reducen los grados de libertad con los que cuentan los sujetos de la sociedad para decidir si cumplen o no la norma, eventualmente "acondicionando" a los sujetos de la sociedad ${ }^{12}$. Limitar los grados de libertad no implica que la concepción del Derecho desde la Teoría de Sistemas Sociales sea una en donde éste simplemente restringe las acciones de las personas, sin buscar el goce efectivo de sus derechos. También el disfrute de los derechos necesita de unas condiciones mínimas en las cuales estos puedan desarrollarse y una violación de estas condiciones mínimas es castigada con una sanción por el Sistema, lo cual implica la garantía de protección del derecho vulnerado.

Puede decirse entonces que las reglas en un sistema jurídico, establecen una expectativa de conducta para los destinatarios de las mismas ( $v$. gr. no torturar). En igual sentido, la aplicación de una norma jurídica es una comunicación de los fines dentro del Sistema Jurídico. Cuando la norma es cumplida, dicho acto genera una comunicación recíproca del sujeto hacia el Sistema, en donde la norma es legitimada por su cumplimiento (siguiendo con el ejemplo, que no se torture legitima la norma de no torturar y recíprocamente el Sistema es legitimado por el sujeto). Bajo el supuesto contrario, el incumplimiento de la norma (el hecho de que se torture)

\footnotetext{
$11 \quad$ BLECKMANN, Frank. Op. cit. p 20.

12 Ibídem.
} 
también representa una comunicación del individuo hacia el Sistema. La diferencia en este caso yace en que la comunicación deslegitima la expectativa normativa. Así, cuando la proscripción es vulnerada, se deslegitiman tanto ésta como el Sistema Jurídico en el que encuentra asidero, lo cual obliga a que la disposición no sólo esté compuesta por la prohibición sino también por una sanción (la condena a los torturadores). Esta sanción funciona como el mecanismo para mantener las expectativas propias a las cuales responde la norma.

\section{ii. Estructuras de auto-legitimación}

Con el fin de comunicar el deber ser que subyace a la norma y configura las expectativas del Sistema, tanto el Sistema Jurídico Internacional como los sistemas jurídicos domésticos, tienen la premisa de encontrar medios de auto-legitimación que le permitan su eficaz reproducción ${ }^{13}$. Dichas herramientas de auto-legitimación pueden clasificarse en estructuras que tienen un carácter principalmente formal y en estructuras que tienen un carácter fundamentalmente material ${ }^{14}$.

Las primeras son aquellas que se encuentran relacionadas con las normas de carácter procedimental, tanto en el proceso de expedición de las fuentes jurídicas (legitimidad de conminación), como en las reglas y garantías procesales comúnmente conocidas en los sistemas jurídicos contemporáneos (legitimidad de imposición) ${ }^{15}$. Por ejemplo, dentro de las reglas de competencia de la Corte Internacional de Justicia se puede encontrar cualificación de la capacidad para ser parte ${ }^{16}$, limitando como sujetos procesales a los Estados ${ }^{17}$. Esta regla obra como una estructura de legitimación formal, particularmente como legitimidad de imposición, debido a que le garantiza a los miembros de la comunidad internacional que únicamente

13 Recuérdese que los sistemas tienen como premisa su reproducción. Véase: BAECKER, Dirk. “¿Por qué una teoría de sistemas?”. En: GÓMEZ JARA DIEZ, Carlos, Op. cit. p. 18.

14 Esta clasificación es pertinente comprenderla con un cierto grado de reserva, ya que se pueden encontrar elementos de legitimación que no encajen de manera clara en alguno de los dos criterios de clasificación, al tener ambos elementos propios. Ver: Peña, Juan Ignacio. "Algunas consideraciones acerca de la (auto) legitimación del derecho penal ¿es el problema de la legitimidad abordable desde una perspectiva sistémico-constructivista?” En: GÓMEZ JARA DIEZ, Carlos, Op. cit. p. 264.

15 Ibídem. p. 266.

16 En este sentido útil es la definición del profesor Hernando Devis Echandía para definir la capacidad para ser parte: "Ser parte en el proceso equivale a ser sujeto de la relación jurídica procesal; por consiguiente, la capacidad para ser parte se identifica con la capacidad de ser sujeto de esa relación como demandante, demandado, interviniente, sindicado, parte civil o ministerio público." Ver: DEVIS ECHANDIA, Hernando. Teoría general del proceso. Tercera Edición. Buenos Aires, Argentina. Editorial Universidad. 2004. p. 531.

17 Artículo 34.1: "1. Sólo los Estados podrán ser partes en casos ante la Corte (...)". Ver: Estatuto de la Corte Internacional de Justicia. 3 Bevans 1179; 59 Stat. 1031; T.S. 993; 39 AJIL Supp. 215 (1945). 
los Estados podrán ser llamados ante la Corte Internacional de Justicia por actos u omisiones que menoscaben los derechos de otros Estados.

Por otro lado, las estructuras de carácter material son aquellas que contienen normas de orden sustancial, como las construcciones dogmáticas sobre el Derecho, los bienes jurídicos a proteger por el sistema penal o el concepto de culpabilidad. Estas construcciones dogmáticas son indispensables para dar predictibilidad al Sistema Jurídico frente a casos futuros en los que se encuentren en juego las mismas expectativas sistémicas ${ }^{18}$.

\section{iii. La teoría de la diferenciación}

El Sistema Jurídico existe dentro de un ecosistema. Este último está compuesto, a nivel macro, por sistemas como el jurídico, el político o el económico. Dentro de la categoría de Sistema Jurídico podemos encontrar asimismo varios grupos diferenciados tales como el Derecho Internacional, el cual se halla en convivencia con los ordenamientos jurídicos domésticos. A partir de esta división al interior del Sistema Jurídico, es necesario que cada uno de estos grupos de elementos establezca unas fronteras claras y perceptibles para los operadores.

Para que la información llegue a estar dentro de las fronteras del Sistema Jurídico Internacional, él debe ser capaz de distinguir las comunicaciones que hacen parte de sí mismo, de las que hacen parte de su entorno o del ecosistema. Dicho de otra manera, para que una comunicación sea parte del Sistema Jurídico Internacional, ésta debe ser diferenciada por el Sistema.

La sociedad está compuesta por diferentes sistemas sociales, como son el sistema jurídico o el sistema político, diferenciados por sus funciones dentro de la misma sociedad $^{19}$. Es así como, cuando se hace referencia al entorno del Sistema Jurídico Internacional, se alude a los demás sistemas sociales ( $v$. gr. los sistemas político y financiero internacionales y el sistema doméstico) que ayudan a que el Sistema Jurídico Internacional se pueda realizar ${ }^{20}$. Para ser más específicos, dentro del entorno del Sistema Jurídico Internacional están las instituciones del sistema político internacional, como es el caso de la Organización de Naciones Unidas, y que recíprocamente ayudan a su funcionamiento. En la Teoría de Sistemas Sociales, el entorno eco-sistémico del ordenamiento jurídico es la suma de todos los otros sistemas que comparten frontera con él. No obstante estas consideraciones iniciales, el Derecho debe entenderse como un sólo sistema cerrado e independiente de su entorno en cuanto a la autoproducción de los elementos que lo componen (como

\footnotetext{
18 PEÑA, Juan Ignacio. Op. cit. pp. 264 y 274.

19 LUHMANN, Niklas, "El derecho como sistema social". En: GÓMEZ JARA DIEZ, Carlos, Op. cit. p. 94.

20 Ibídem.
} 
las estructuras de legitimación), autoproducción que dentro de la teoría de sistemas sociales es conocida como autopoiesis.

Ahora, esto no significa que el Sistema Jurídico se encuentre aislado de otros sistemas como el político o el económico, ya que para la realización de sus actuaciones indefectiblemente requerirá de su apoyo. Por ejemplo, se necesita del sistema político para que promulgue leyes, así como este último necesita del jurídico para limitar los poderes de sus actores. Como consecuencia de su interdependencia, puede haber operadores que generen comunicaciones dentro de ambos sistemas. No sobra aclarar que la interdependencia sistémica para la realización de las actuaciones propias de cada grupo es distinta al lenguaje propio, entendido este como la habilidad del Sistema de producir sus propios elementos.

Antes de presentar la explicación del concepto autopoiesis, es importante establecer con precisión cómo el Sistema Jurídico Internacional se diferencia de los otros sistemas con los que comparte fronteras. Dicha distinción debe hacerse a través de una cláusula referencial ${ }^{21}$. Esta cláusula, que podría bien operar en la exclusión de pruebas de litigios internacionales, es un código binario que el Sistema le aplica a una comunicación para hacerla parte de sí mismo o tomarla como irrelevante. El código binario que se aplica es, por ejemplo, lícito/ilícito, legal/ilegal, coherente con el Derecho Internacional/incoherente con el Derecho Internacional.

\section{iv. La autopoiesis}

Para que un sistema pueda ser percibido como tal desde la teoría formulada por Luhmann, debe ser autopoiético. Etimológicamente la palabra autopoiesis viene del

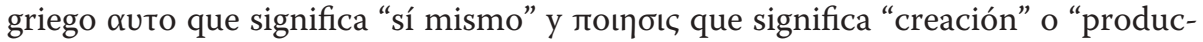
ción". Lo anterior se enmarca en una de las características más importantes de la Teoría de Sistemas Sociales propuesta por Luhmann, esta es, la capacidad que tiene el Sistema para la autorreproducción ${ }^{22}$. El Sistema necesita reproducir, como un organismo que genera sus propias células, los elementos que lo componen. En el caso del Sistema Jurídico Internacional, algunos de los elementos que lo integran son las normas de Derecho Internacional. Por lo tanto, para que aquél sea autopoiético debe ser capaz de producir sus propias normas sustanciales y procesales. Este interesante planteamiento pone en evidencia la verdadera importancia de la autopoiesis en los sistemas, dado que ante eventuales irritaciones producidas por el entorno, sean estas exógenas o endógenas, su forma de proceder será predecible ${ }^{23}$. Dicho sea de paso que la configuración legislativa no proviene únicamente de las fuentes estrictamente positivizadas, como los tratados, ya que la jurisprudencia a

\footnotetext{
$21 \quad$ Ibídem. p. 93.

22 PEÑA, Juan Ignacio. Op. cit. p. 260.

23 KARGL, Walter. “¿Sociedad sin sujetos o sujetos sin sociedad? Una crítica a la crítica de la autopoiesis social”. En: GÓMEZ JARA DIEZ, Carlos, Op. cit. p. 63.
} 
nivel internacional cumple la doble función de aplicar y a la vez precisar el contenido de las normas escritas.

Es preciso aclarar, y como bien se anotó en líneas anteriores, que la Teoría de Sistemas Sociales encuentra su asidero conceptual en la biología. Sin embargo, Luhmann extrapoló dicha teoría a lo social, lo que implica que la idea de autopoiesis (propia de los sistemas biológicos) es complementada por una noción de contenido más social como la autorreferencialidad. Sobre el particular el profesor Kargl parafraseando las palabras del sociólogo Gerhard Roth precisa lo siguiente:

\begin{abstract}
"Los sistemas autorreferenciales son, por tanto, sistemas que modifican las situaciones de sus componentes mediante una cláusula operacional. Frente a su entorno son relativamente autónomos, por lo que sólo de forma limitada pueden ser conducidos desde fuera. Sin embargo, se trata en estos casos no de sistemas "libres" sino de sistemas determinados en el sentido de que van alcanzando una sucesión de estados fijada de antemano -aunque sea por el propio sistema-: son sistemas determinados internamente o determinados por su estado"24.
\end{abstract}

Así, al hablar de sistemas cognitivos (en contraposición con los sistemas biológi$\cos$ ) es preciso referirse a la autorreferencialidad, característica propia en virtud de la cual el Sistema se auto-cita, esto es, observa sus normas procesales y sustanciales pertinentes para llevar a cabo la autopoiesis (promulgar y comunicar nuevas normas) con el fin de cambiar y adaptarse de acuerdo con las exigencias de su entorno y de sus propios fines.

\title{
v. Los operadores del Sistema
}

Una de las críticas tradicionales que se le hace a la Teoría de Sistemas está fundada en la idea de que la misma "deshumaniza" al Derecho ${ }^{25}$, es decir que no se preocupa lo suficiente por explicar cuál es su relación con los jueces, abogados y partes. A menudo, la Teoría de Sistemas Sociales hace alusión a las operaciones que hace el Sistema, pero no profundiza detalladamente sobre el concepto de operador como sujeto capaz de producir comunicaciones relevantes. Para superar este obstáculo, la teoría del filósofo John R. Searle explica con precisión quiénes son los operadores del Sistema.

Searle, en su obra "The Construction of Social Reality”, argumenta la existencia de algo que bautiza como poderes deónticos ${ }^{26}$. De acuerdo con el autor, los poderes deónticos son un atributo que adquieren las personas para regular relaciones entre

$24 \quad$ Ibidem. p. 67.

25 BAECKER, Dirk. “¿Por qué una teoría de sistemas?”. En: Gómez Jara Diez, Carlos, Op. cit. p. 19.

26 SEARLE, John. The Construction of Social Reality. Primera Edición. Nueva York. The Free Press. 1995. p. 100. 
$s^{127}$. Gracias a la imposición de poderes deónticos, estos atributos se traducen en derechos, obligaciones, autorizaciones, deberes, privilegios, condenas y certificaciones, entre otros ${ }^{28}$. Para Searle se pueden hacer dos categorizaciones generales de los poderes deónticos: por un lado, están los poderes que dan un derecho, privilegio, certificación, permiso, crédito o cualidad que garantiza la habilidad del sujeto de hacer algo; por otra parte, están los poderes que obligan, endeudan o penalizan a un sujeto $^{29}$. De esta manera, los operadores del sistema son sujetos que han recibido los poderes deónticos relacionados con los títulos de abogado, juez, accionante, demandante, demandado, etc., según corresponda. Estos son títulos que el mismo Sistema prevé en su normatividad para darle paso a que el entorno, representado por los sujetos, pueda acceder a él.

Ahora, haber recibido los poderes deónticos significa estar en capacidad de generar operaciones dentro de un grupo de elementos particular, sin embargo, un operador del Sistema Jurídico puede ser a su vez operador de otro sistema. Por ejemplo, un Ministro de Hacienda puede presentar proyectos de ley ante el Senado de la República (poder deóntico para actuar en el Sistema Político) y a la vez puede demandar la resolución de un contrato (poder deóntico para actuar en el Sistema Jurídico). Esta dualidad no significa que el Sistema Jurídico no sea cerrado en cuanto a la producción de los elementos que lo componen, dado que las dos facultades son autónomas y en el ejemplo visto, no se necesita ser Ministro para tener la capacidad procesal para presentar una demanda.

\section{vi. La teoría de la evolución del sistema}

Gracias a la idea de la autopoiesis y a la cláusula referencial es posible conectar la Teoría de Sistemas con la teoría de la evolución ${ }^{30}$. Cada vez que el Sistema va reproduciendo sus propios elementos, él mismo va cambiando y evolucionando. Para el Sistema Jurídico Internacional la evolución consiste en la promulgación de nuevas normas y la derogación de las antiguas. Lo que provoca entonces la evolución del Sistema es su necesidad de resolver cuáles expectativas normativas se pueden mantener y cuáles no ${ }^{31}$. Así, el Sistema Jurídico Internacional va cambiando según el éxito que las expectativas normativas tengan en la sociedad. Dicho de otra manera, el entorno del Sistema va generando impulsos que llevan a la evolución del mismo ${ }^{32}$; el cumplimiento o incumplimiento de una expectativa normativa genera que el Sistema decida mantener o descartar dicha expectativa.

\footnotetext{
$27 \quad$ Ibídem. p 80

28 Ibídem.

29 Ibídem.

30 LUHMANN, Niklas. p. 103.

31 Ibídem.

32 Ibídem.
} 
El Sistema Jurídico Internacional como sistema evolucionado desarrolla criterios de selección que son limitados por sus mismos intereses. Ello deriva en que no solamente sea posible su evolución progresiva, sino que también sea necesaria.

\section{De la prueba IlíCita O ILegal EN EL Derecho INTERNACIONAL Y SU CONTRASTE CON EL DERECHO INTERNO}

Habiendo explicado la forma como el Sistema va evolucionando, es pertinente aclarar que dicha evolución se produce a partir de la introducción de nuevas ideas, las cuales se pueden aprender desde los alcances de otros sistemas jurídicos como es el caso de los sistemas domésticos. La razón por la cual nos referimos al Sistema de Derecho colombiano es porque se trata de un sistema que ha logrado diferenciar entre ilegalidad e ilicitud de la prueba y, en esa medida, como se verá a continuación, ha alcanzado mayor precisión y seguridad jurídica que el Sistema Internacional. No obstante, las consideraciones sobre Derecho interno también darán cuenta de fenómenos en los cuales las reglas preestablecidas han debido flexibilizarse o de casos donde el juez ha basado su fallo en evidencia que inicialmente calificó como inadmisible.

Valga la pena aclarar que a pesar de que los sistemas nacionales e internacionales cuentan con diferentes operadores y responden a lógicas esencialmente distintas, ambos hacen parte de un entorno en el cual interactúan y se nutren recíprocamente, tal y como se expuso en el capítulo anterior. En ese sentido, las dinámicas sobre admisión de la prueba a nivel internacional no sólo son comparables con las domésticas sino que son necesarias para la evolución de los sistemas de Derecho.

\section{i. De la prueba ilícita e ilegal en el Derecho interno colombiano}

El Sistema Jurídico colombiano ofrece diversas referencias en relación con la prueba ilícita. La Carta Política, en el último inciso de su artículo 29, reza: "Es nula, de pleno derecho, la prueba obtenida con violación del debido proceso”. En armonía con ello, el artículo 178 del Código de Procedimiento Civil ha señalado que "Las pruebas deben ceñirse al asunto materia del proceso y el juez rechazará in limine las legalmente prohibidas o ineficaces" ${ }^{\prime 3}$. Por su parte, el Código de Procedimiento Penal en su artículo 360, prescribe que el juez debe excluir la práctica o aducción de medios

33 A la fecha de elaboración del presente documento, las disposiciones del Código General del Proceso (Ley 1564 de 2012) que versan sobre el tema en cuestión, aún no han entrado en vigencia. Las siguientes son las referencias del nuevo Código a la regla de exclusión: i) Artículo 14. "DEBIDO PROCESO. El debido proceso se aplicará a todas las actuaciones previstas en este código. Es nula de pleno derecho la prueba obtenida con violación del debido proceso." ii) Artículo 168. "RECHAZO DE PLANO. El juez rechazará, mediante providencia motivada, las pruebas ilícitas, las notoriamente impertinentes, las inconducentes y las manifiestamente superfluas o inútiles." 
de prueba ilegales, incluyendo los que se han practicado, aducido o conseguido con violación de los requisitos formales.

La jurisprudencia ha precisado el contenido de la regla de exclusión probatoria al diferenciar lo que se considera como pruebas legalmente prohibidas, ilícitas e ilegales. En la jurisdicción civil, la decisión del 28 de abril de 2008 de la Sala de Casación Civil de la Corte Suprema de Justicia ${ }^{34}$ explica cómo a través de la figura de las pruebas legalmente prohibidas, se inserta en esa materia el control de las pruebas ilegales e ilícitas:

"No sobra precisar, en todo caso, al margen de lo dicho, que un primer momento de control de la prueba ilícita, quizás el más idóneo, se encuentra en el mandato contenido en el artículo $178 \mathrm{del}$ C. de P. C., conforme al cual, el juez "rechazará in limine las (pruebas) legalmente prohibidas (...) no toda prohibición probatoria apareja de manera ineludible la ilicitud de la prueba, pues así sucederá en cuanto la veda esté enderezada a tutelar garantías fundamentales. Se dice que es el más idóneo de los mecanismos de repulsión de la prueba ilícita porque imposibilita la contaminación psicológica del juzgador, al impedir, desde el pórtico, el ingreso del elemento de convicción."

En éste mismo fallo, el Tribunal contrasta lo que se considera una prueba ilícita con una prueba ilegal:

"Refulgen diversos criterios de distinción entre la prueba ilícita y la ilegal, pues, en primer lugar, aquélla presupone la vulneración de normas constitucionales, o de ese linaje, que consagren derechos fundamentales; mientras que esta otra (la ilegal), apareja la trasgresión de preceptos legales o de igual o inferior jerarquía; así mismo, que el defecto que estigmatiza una prueba ilícita es insubsanable, a la vez que no pueden aplicarse respecto de ella los diversos mecanismos de convalidación que pueda prever el ordenamiento, mientras que los defectos que acuse la prueba ilegal pueden ser, por el contrario, subsanados e, inclusive, puede acontecer que a pesar de la irregularidad el elemento persuasivo no sufra menoscabo. Por último, la exclusión de la prueba derivada de aquélla que es anómala solamente acaece en los casos de prueba ilícita, pero no en los de ilegalidad de la misma."35

Por su parte, la Sala de Casación Penal de la Corte Suprema de Justicia, en providencia de octubre 21 de $2009^{36}$, también explica la diferencia entre las pruebas ilegales y las ilícitas, así:

34 Colombia. Corte Suprema de Justicia. Sala Civil y Agraria, Sentencia de Casación No. del 28 de abril de 2008. M.P Pedro Octavio Mudar Cadena. Expediente No. 110010203000200300097 01 .

35 Ibídem.

36 Colombia. Corte Suprema de Justicia. Sala penal, Sentencia de Casación del 21 de octubre de 2009. M.P Yesid Ramírez Bastidas. Proceso No. 32193. 
"Se entiende por prueba ilícita la que se obtiene con vulneración de los derechos fundamentales de las personas, entre ellos la dignidad, el debido proceso, la intimidad, la no autoincriminación (...) La prueba ilegal se genera cuando en su producción, práctica o aducción se incumplen los requisitos legales esenciales, caso en el cual debe ser excluida como lo indica el artículo 29 Superior".

Así mismo, en esta última sentencia se explica la regla de exclusión de las pruebas ilícitas o ilegales, afirmando que a pesar de ser diferentes en su naturaleza, producen la misma consecuencia jurídica: la inexistencia de la prueba ilícita o ilegal:

“(...) Se debe considerar que tanto en los eventos de ilicitud y de ilegalidad probatoria como de ilicitudes o ilegalidades que recaen sobre los elementos materiales probatorios y evidencias físicas lo que se produce normativamente son efectos idénticos de exclusión dadas las inexistencias jurídicas por tratarse en esos eventos de medios de convicción que constitucionalmente se predican "nulos de pleno derecho" y que, en consecuencia, dichos resultados de "inexistencia jurídica" se transmiten a los que dependan o sean consecuencia de aquellos o a los que sólo puedan explicarse en razón de la existencia de las excluidas, pues como es de lógica jurídica y por sobre todo constitucional, las "inexistencias jurídicas" no pueden dar lugar a "reflejos de existencias jurídicas".

Como consecuencia de la inexistencia de la prueba, es menester que la regla de exclusión de pruebas ilegales o ilícitas no se aplique de forma mecánica, ya que el juez debe ponderar entre la omisión normativa y las consecuencias que esto implica para el proceso. Tal como señala la Corte Suprema de Justicia, "corresponde al juez determinar si el requisito legal pretermitido es esencial y discernir su proyección y trascendencia sobre el debido proceso, toda vez que la omisión de alguna formalidad insustancial, por sí sola no autoriza la exclusión" ${ }^{\text {"37. }}$

Este mismo criterio de interpretación sobre las formalidades legales esenciales para aplicar la regla de exclusión se encuentra en la sentencia C-491 de 1995, proferida por la Corte Constitucional:

"...que además de dichas causales legales de nulidad (consagradas en el artículo 140 del Código de Procedimiento Civil) es viable y puede ser invocada la consagrada en el art. 29 de la Constitución, según el cual "es nula, de pleno derecho, la prueba obtenida con violación del debido proceso", esto es, sin la observancia de las formalidades legales esenciales requeridas para la producción de la prueba, especialmente en lo que atañe con el derecho de contradicción por la parte a la cual se opone ésta. Por lo tanto, se declarará

37 Colombia. Corte Suprema de Justicia, Sala de Casación Penal, Sentencia de casación del 2 de marzo de 2005. M.P Edgar Lombana Trujillo. Proceso No. 18.103. 
exequible la expresión demandada, con la referida advertencia"38 (Paréntesis fuera de texto).

\section{ii. Excepciones en materia probatoria a la regla de exclusión del Derecho nacional}

En la jurisprudencia de la Corte Suprema de Justicia, hay casos en los cuales se admite una prueba ilegal o ilícita en el acervo probatorio de un proceso. Por ejemplo, en aquellos eventos en los cuales el sujeto pasivo de un delito registre en algún medio magnetofónico la acción delictiva, la Corte Suprema ha aceptado que este tipo de pruebas sean incluidas dentro del proceso a pesar de no haber sido obtenidas en estricto sometimiento a los requisitos legales ${ }^{39}$.

Tal como señaló la sala de casación penal de la Corte Suprema de Justicia en la providencia del 22 de octubre de 1996:

"Valga la oportunidad para que la sala actualice el planteamiento expuesto en sentencia del 16 de marzo de 1998...mal podría esgrimirse impedimento alguno o exigir autorización judicial para que las personas graben su propia voz o su imagen, o intercepten su línea telefónica, si estas actividades no se hallan expresamente prohibidas. Este aserto resulta avalado si se tiene en cuenta que quien así actúa es precisamente el afectado con la conducta ilícita, y por ende, eventualmente vulneradora de sus derechos fundamentales, por lo que su proceder se constituye en un natural reflejo defensivo" ${ }^{\prime \prime 0}$.

Así mismo, el Código de Procedimiento Penal en su artículo 455 contempla que la aplicación de su artículo $23^{41}$ debe hacerse teniendo en cuenta los criterios del "vínculo atenuado, la fuente independiente, el descubrimiento inevitable y los demás que establezca la ley". Estos criterios de interpretación, que permiten de manera excepcional la admisión de una prueba ilícita o ilegal, fueron establecidos originalmente por la doctrina y jurisprudencia extranjeras ${ }^{42}$, incursionando al siste-

38 Colombia. Corte Constitucional, Sentencia C-491 del 2 de noviembre de 1995. M.P Antonio Barrera Carbonell. Expediente D-884.

39 Una interceptación magnetofónica debe ser ordenada por la fiscalía (art 114 numeral 3 del $\mathrm{CPP}$ ) y luego ser cometida a un proceso de legalización en audiencia ante autoridad judicial (art 237 del CPP).

40 Ver comentarios a la Sentencia del 22 de octubre de 1996 de la Corte Suprema de Justicia. En: Quijano Parra, Jairo. Manual de Derecho Probatorio. Decimoséptima edición. Bogotá, Librería Ediciones del Profesional Ltda. 2009. p. 40

41 Este artículo define la Claúsula de exclusión de la siguiente manera: "Cláusula de exclusión. Toda prueba obtenida con violación de las garantías fundamentales será nula de pleno derecho, por lo que deberá excluirse de la actuación procesal. Igual tratamiento recibirán las pruebas que sean consecuencia de las pruebas excluidas, o las que solo puedan explicarse en razón de su existencia".

42 La jurisprudencia de la Corte Suprema de los Estados Unidos desarrolló inicialmente estos criterios. Por ejemplo, el criterio del descubrimiento inevitable fue desarrollado en el caso Nix 
ma jurídico colombiano a través de la jurisprudencia y doctrina nacionales antes de su consagración en el Código de Procedimiento Penal ${ }^{43}$.

La constitucionalidad del artículo 455 fue analizada por la Corte Constitucional en su sentencia C-591/05, en la cual se discutió la relación entre el artículo 29 de la Carta Política, el artículo 23 del Código de Procedimiento Penal y el artículo 455 ibídem. En primer lugar, la Corte estableció la relación entre el artículo 29 de la Constitución y el artículo 23 del precitado Código. Sobre el particular dijo esa Corporación:

“(...) esta norma general no se opone al artículo 29 Superior, y por el contrario lo reafirma, al disponer la nulidad de pleno derecho de la prueba y su exclusión cuando ha sido obtenida con violación de las garantías fundamentales, así como las que sean consecuencia de las pruebas excluidas; es decir, se refiere a la nulidad de pleno derecho y la exclusión del proceso de la prueba obtenida contrariando la Constitución, la que según lo considerado por la Corte, es una fuente de exclusión de la prueba de conformidad con el artículo 29 Superior."44

En consecuencia, la Sala declaró la constitucionalidad del artículo 455 al considerar que:

"[E]l legislador, actuando dentro de su margen de configuración normativa, reguló un conjunto de criterios que le servirán al juez para realizar una ponderación cuando deba proceder a excluir de la actuación procesal pruebas derivadas, (...) Así las cosas, para la Corte es claro que, en virtud del artículo 29 constitucional, se debe excluir cualquier clase de prueba, bien sea directa 0 derivada, que haya sido obtenida con violación de las garantías procesales y los derechos fundamentales. En tal sentido, los criterios que señala el artículo 455 de la Ley 906 de 2004 para efectos de aplicar la regla de exclusión se ajustan a la Constitución por cuanto, lejos de autorizar la admisión de pruebas derivadas ilegales o inconstitucionales, apuntan todos ellos a considerar como admisibles únicamente determinadas pruebas derivadas que provengan de una fuente separada, independiente y autónoma, o cuyo vínculo con la prueba

vs. Williams. Ver: Estados Unidos. Corte Suprema. Caso Nix vs. Williams, 467 U.S. 431, 443-44 (1984).

43 Tal como lo comenta la Corte Suprema de Justicia colombiana: "Y aunque es claro que el presente asunto se rige por el Código de Procedimiento Penal, Ley 600 de 2000, y sin que de ninguna manera se trate de combinar para este caso ordenamientos jurídicos distintos, se estima oportuno recordar que los mismos parámetros, que antes sólo eran doctrinarios y jurisprudenciales, fueron adoptados por el legislador colombiano en el Código de Procedimiento Penal para el sistema acusatorio, Ley 906 de 2004, como excepciones que permiten admitir la validez de una prueba lícita derivada de una prueba ilegal o ilícita". Colombia. Corte Suprema de Justicia. Sala penal. Sentencia de Casación del 5 de Octubre de 2006. M.P Javier Zapata Ortiz. Proceso No 23284 .

44 Colombia. Corte Constitucional, Sentencia C-591/05. 9 de junio de 2005. M.P Clara Inés Vargas Hernández. Expediente D-5415. 
primaria inconstitucional o ilegal sea tan tenue que puede considerarse que ya se ha roto" ${ }^{\text {"45 }}$ (Subrayas fuera del texto original).

En contraposición a la aparente claridad que existió por algunos años en las altas cortes colombianas sobre el valor probatorio de evidencia irregularmente obtenida, cabe estudiar el auto inhibitorio a favor del ex Representante a la Cámara de Representantes Wilson Borja, proferido por la sala penal de la Corte Suprema de Justicia el 18 de mayo de 2011 y confirmado por esa corporación el 1 de agosto de ese mismo año. ${ }^{46}$.

Según la Corte, las pruebas encontradas en el computador del líder guerrillero Raúl Reyes, abatido en la "Operación Fenix" que se llevó a cabo en Ecuador, debían excluirse del acervo probatorio por considerarse ilegales. Esta decisión aplicó la regla de exclusión inadmitiendo las pruebas documentales mencionadas, debido a que las mismas fueron obtenidas en un país extranjero sin acatar lo establecido por las normas de procedimiento penal colombiano (arts. $499^{47}, 502^{48}, 503^{49}$ y $505^{50}$ ), la Carta Política (arts 2951, 10152), así como obligaciones internacionales ("Convenio de Cooperación Judicial y Asistencia Mutua en Materia Penal Entre la República de Colombia y la República de Ecuador") ${ }^{53}$.

El fallo en mención genera una serie de problemas que se encontraban ya resueltos respecto del contenido de la regla de exclusión. Primero, si bien la Corte se inhibió de abrir investigación y declaró la ilegalidad de la evidencia obtenida en el exterior, se refirió a estas pruebas en su fallo, divulgando parcialmente el contenido de los documentos electrónicos descubiertos en los equipos de almacenamiento ${ }^{54}$. El empleo de la prueba que ya había sido inadmitida tuvo como propósito fortalecer el alegato de que no se había demostrado la relación entre el ex representante y el grupo guerrillero.

La segunda inquietud que surge de la decisión analizada se refiere a las expectativas de respuesta del Sistema en casos futuros similares. Cabe recordar que este proceso hace parte de un selecto número de casos que tienen una naturaleza híbri-

\footnotetext{
45 Ibídem.

46 Colombia. Corte Suprema de Justicia, Sala Penal, Providencia que resuelve recurso de reposición. 1 de agosto de 2011. Expediente No. 29.877.

47 Colombia. Corte Suprema de Justicia, Sala de Casación Penal, Auto Inhibitorio del 18 de agosto de 2011. Expediente No. 29.877. Párr. 24.

48 Ibídem. párr. 24.

49 Ibídem. párr. 25.

$50 \quad$ Ibídem. párr. 25.

$51 \quad$ Ibídem. párr. 38.

$52 \quad$ Ibidem. párr. 19.

$53 \quad$ Ibídem. párr. 28.

$54 \quad$ Ibídem. párr. 39.
} 
da, es decir, que siendo juzgados por operadores jurídicos del sistema doméstico resuelven sobre cuestiones que usualmente hacen parte de las comunicaciones propias del Derecho Internacional tales como soberanía o cooperación judicial entre Estados. A continuación realizaremos algunas consideraciones sobre el Sistema Jurídico Internacional en torno a la prueba ilegal.

\section{iil. Prueba ilegal en el Derecho Internacional}

En asuntos procesales, comúnmente se ha percibido el litigio internacional como un modelo idéntico a las normas procedimentales domésticas. Poca consideración se le ha dado al hecho de que tal percepción es imprecisa e insuficiente al trasladarse a un plano internacional ${ }^{55}$. Debe tenerse en cuenta que las reglas aplicables a cortes internacionales son diferentes a las usadas en tribunales nacionales. El Sistema Internacional de Justicia cuenta con una característica esencial a todo sistema cual es su autonomía reflejada en la habilidad de diferenciarse de otros grupos de su entorno. Lo anterior sin embargo, no impide de ninguna manera que el Sistema de Derecho Internacional establezca comunicaciones y comparaciones con los sistemas domésticos. De hecho y como hemos sostenido durante el desarrollo de este trabajo, tales comunicaciones recíprocas con el entorno permiten el cambio al interior de sistemas autopoiéticos.

La evidencia ilegal se denomina de esta manera ya que nace o se obtiene de un acto contra el sistema jurídico en sí mismo, o por fuera de "las comunicaciones aceptables" bajo la lógica de sistemas. En ese sentido, la evidencia obtenida a través de medios que vulneren un bien jurídico de vital importancia para la comunidad internacional, comporta una actuación a la que se le aplica la codificación de ilegal y en consecuencia, le debe ser aplicable una sanción que ha de ser su inadmisión. En el Sistema Jurídico Internacional, existen dos representaciones claras de evidencia obtenida ilícita o ilegalmente: la evidencia obtenida bajo tortura, generalmente de carácter testimonial; y la evidencia obtenida mediante irrupción de la soberanía de un Estado, generalmente de carácter documental.

\section{i. Pruebas obtenidas bajo tortura: de la Torture Exclusionary rule en el escenario internacional}

La regla consiste en la exclusión de evidencia obtenida bajo tortura. Fue consignada en el artículo 15 de la "Convención de Naciones Unidas contra la tortura u otros tratos crueles, inhumanos o degradantes" que fue adoptada en el año 1984 y de la cual son parte 153 países. Adicionalmente, el "Cuerpo de Principios de protección

55 Thirlway, Hugh. "Dilemma or Chimera? Admissibility of Illegally Obtained Evidence in International Adjudication". The American Journal of International Law, Vol. 78, No. 3 (Jul., 1984), pp. 622-641. 
de todas las personas bajo cualquier forma de detención o encarcelamiento"56, aprobado por la Asamblea General de las Naciones Unidas en septiembre de 1990, establece en el principio 16 que los fiscales se deben rehusar a emplear evidencia obtenida "bajo tortura o maltrato excepto en procedimientos en contra de quienes estén acusados de usar tales métodos". La razón detrás de esa exclusión es que la aceptación por parte de un adjudicador de una declaración o testimonio obtenido bajo tortura podría llegar a fomentar dicha práctica, por lo que inadmitir evidencia obtenida de esta forma hace de la conducta algo poco atractivo y por supuesto, no remunerado por el Sistema ${ }^{57}$.

Algunos tribunales han incluido esta regla de exclusión. El Tribunal Penal Internacional de Ruanda en su regla de procedimiento $95^{58}$, estipula que se puede realizar la exclusión de la evidencia obtenida con base en métodos que levanten dudas sustanciales sobre su confiabilidad y que puedan generar serio daño a la integridad de los procedimientos. Por su parte, el Tribunal de Sierra Leona en su regla 95 de procedimiento, consagra que la evidencia no será admisible si su aceptación acarrea serias disrupciones a la administración o a la justicia ${ }^{59}$. En otro proceso de justicia criminal transicional ${ }^{60}$, se establece que la Corte podría excluir evidencia si su valor probatorio cede frente a su efecto perjudicial y ninguna prueba podría ser admitida si se obtuvo por medios que despierten dudas sobre una posible admisión "anti-ética".

Ahora bien, puede presentarse que el establecimiento de tribunales $A d-H o c$ no refleje las reglas aplicables dentro de la nación donde operan. Es así como, si bien un Estado pudo haber ratificado la Convención sobre la tortura, las reglas del Tribunal pueden haberla obviado por completo ${ }^{61}$. Sin embargo, la forma para vincular al

56 Cuerpo de Principios para la Protección de Todas las Personas bajo cualquier forma de Detención o Encarcelamiento. GA res. 43/173, annex, 43 UN GAOR Supp. (No. 49) at 298, UN Doc. A/43/49 (1988).

57 ONU. Consejo Económico y Social, Comisión de Derechos Humanos. Informe del relator especial Peter Kooijmans, Reporte sobre "Derechos Humanos de todas las personas sometidas a cualquier forma de detención o prisión y en particular: la tortura y otros tratos o penas crueles, inhumanas o degradantes", U.N. Doc, E/CN.4/1993/26 (Dic. 15, 1992) (En la Sesión 49 de la Comisión de Derechos Humanos).

58 Tribunal Penal Internacional para Ruanda. Reglas de Procedimiento y Evidencia. Regla 95. U.N. Doc. ITR/3/REV.1 (1995).

59 Estatuto del Tribunal Especial para Sierra Leona. 2178 UNTS 138, 145; 97 AJIL 295; UN Doc. S/2002/246, appendix II.

60 ONU. Administración de Justicia Transicional en Timor Oriental. Reglamento No. 2000/30 Sobre Normas Transicionales de Procedimiento Penal. UNTAET/Reg/2000/30. párr. 34.2.

${ }_{61}$ SHARF, Michael. "Tainted Provenance: When, If Ever, Should Torture Evidence be admissible?” Washington and Lee Law Review. Volumen. 129. 2008. Lexington. Washington and Lee University School of Law. p. 135. 
Tribunal a normas nacionales que sí la consagren, podría darse mediante el artículo 31(3) (c) de la Convención de Viena sobre el Derecho de los tratados, que establece que: "al interpretar un tratado, la parte deberá tomar en consideración, junto con el contexto, cualquier regla de Derecho Internacional aplicable en relación entre las partes" $^{\prime 2}$. Lo anterior reforzado con el hecho de que la prohibición de la tortura ya ha alcanzado el rango de Ius Cogens. Esto es una manifestación del control de información que ejerce el Sistema sobre las comunicaciones y de cómo restringe los grados de libertad de sus operadores.

\section{ii. Exclusión de pruebas obtenidas mediante tratos crueles, inhumanos o degradantes}

En el año 2005 se implementó en los Estados Unidos una excepción a la mencionada regla a través de una regulación de los interrogatorios a detenidos en Guantánamo. Si bien uno de los propósitos explícitos de la norma era prohibir los "tratos crueles, inhumanos y degradantes", en realidad no le otorgó ningún contenido a esa expresión, dejándolo al arbitrio de quienes debían obtener las confesiones ${ }^{63}$. De ahí surgió una modificación a la regla de exclusión que facultaría la utilización de pruebas obtenidas por métodos, que a pesar de ser controversiales, no se podrían calificar como tortura o tratos crueles, inhumanos y degradantes. Posteriormente la Corte Suprema de Estados Unidos se referiría a esta ley en el caso Boumediene vs. Bush declarando que limitaba significativamente el derecho al Habeas Corpus y que no ofrecía un sustituto adecuado a este derecho ${ }^{64}$.

La primera distinción entre tortura y tratos crueles, inhumanos y degradantes se hizo en el caso Irlanda contra el Reino Unido donde el Tribunal Europeo de Derechos Humanos (en adelante TEDH o Tribunal) reconoció la existencia de cinco técnicas que generaban un trato cruel, inhumano y degradante, pero que no llegaban al nivel de tortura ${ }^{65}$. En el caso de Selmouni contra Francia, el TEDH encontró que las humillaciones sexuales constituían tortura. En este mismo caso, el Tribunal determinó que la Convención sobre Tortura era un "organismo vivo"66 que debía adaptarse a las circunstancias de un mundo cambiante, es decir, que el mecanismo de auto legitimación material que definía el concepto de tortura se encontraba en constante evolución, respondiendo a los cambios del entorno.

\footnotetext{
62 Convención de Viena sobre el Derecho de los Tratados. Op. cit.

63 Estados Unidos. Detainee Treatment Act of 2005. Department of Defense Appropriations Act of 2006 (Title X, H.R. 2863). Diciembre 18 de 2005. Secciones 1003 y 1004.

64 Estados Unidos. Corte Suprema. Boumediene vs. Bush, 553 U.S. 723 (2008).

65 TEDH, Caso Irlanda Vs. Reino Unido, (No. 5310/71), Sentencia de 18 de enero de 1978, párr. 165-168.

66 TEDH, Caso Selmouni Vs. Francia, (No. 25803/94), Sentencia del 28 de julio de 1999, párr. 101.
} 


\section{iii. Pruebas obtenidas bajo intervención Estatal}

Se ha reconocido que en el escenario internacional que, a diferencia de lo que ocurre en algunos sistemas domésticos como en el anglosajón, los jueces o adjudicadores carecen de la capacidad suficiente para obligar a alguna de las partes a aportar evidencia al caso ${ }^{67}$. Hace algún tiempo las Cortes intentaban sancionar indirectamente a quien no cumpliese el mandato de aportar la prueba requerida mediante un indicio en su contra ${ }^{68}$. El artículo 49 de la antigua Corte Permanente Internacional de Justicia estableció que la sanción en esos casos se materializaba en que el Tribunal tomaría nota de esa negación. Actualmente, el artículo 50 del estatuto de la Corte Internacional de Justicia le otorga la posibilidad de requerir información de cualquier organismo, individuo, o comisión que ayude a su convicción. De la misma forma, los artículos 48 y 49 le permiten obtener respuestas o explicaciones por parte de los agentes de cada Estado y de hacerlo antes de que el proceso inicie.

A pesar de lo anterior, lo cierto es que los operadores del sistema que requieren alguna evidencia en el contexto internacional usualmente carecen de las facultades suficientes para lograr que sea aportada por quien la tiene. Esto conlleva a que en ciertos casos, la obtención de la prueba se realice desatendiendo los principios que rigen la materia, entre los que se encuentra, por ejemplo, la obligación internacional de respetar la soberanía de los Estados consagrada en el artículo 2.1 de la Carta de las Naciones Unidas.

A continuación nos referiremos a uno de los casos emblemáticos sobre el uso de acciones militares unilaterales con el propósito de recolectar evidencia en otro territorio: el fallo de 1949 del Canal de Corfú por parte de la Corte Internacional de Justicia. Si bien este caso fue decidido por un tribunal que conoce de litigios entre Estados, es necesario estudiar esta decisión de méritos con el fin de ampliar sobre los antecedentes históricos en Derecho Internacional acerca del empleo de evidencia obtenida ilegalmente. De igual manera cabe aclarar que el estudio particular sobre cortes o tribunales internacionales que se encuentra en los siguientes acápites lo hemos limitado a aquellos organismos que se pronuncian en casos de violaciones de Derechos Humanos o de Derecho Internacional Humanitario.

El 22 de Octubre de 1946, dos buques británicos Saumarez \& Volage fueron golpeados por minas submarinas en las aguas territoriales de Albania. El 13 de noviembre de 1946, la fuerza naval británica, entró al territorio soberano de Albania

67 Reisman, W. Michael y Freedman, Eric E. Op. cit. 738.

68 Hasan Shah, Nasim. "Discovery by Intervention: The Right of a State to Seize Evidence Located within the Territory of the Respondent State". The American Journal of International Law, Volumen. 53. 1959. American Society of International Law Stable. En: http://www.jstor.org/ stable/2195390. Consultado el 18/10/2012. p. 595. 
con el propósito de limpiar el suelo del canal de Corfú en lo que fue denominado la "Operación retail" la cual fue considerada por el gobierno albanés como una irrupción arbitraria. El gobierno británico justificó sus acciones estableciendo que eran medidas urgentes y necesarias para garantizar la integridad de los medios probatorios y esclarecer la muerte de 44 marinos ingleses producida por minas presentes en el mar de Albania ${ }^{69}$.

En ninguno de los escenarios donde se planteó la posibilidad de barrer el suelo del Canal de Corfú, el gobierno de Gran Bretaña reconoció que tenía intenciones de recolectar evidencia para preparar un caso en contra de Albania. Fue solo hasta septiembre de 1947 que, en un memorial dirigido a la Corte Internacional de Justicia, el país británico reconoció las intenciones reales de la "Operación retail"70.

En el presente caso, con ocasión al tema de la admisibilidad de pruebas obtenidas de manera ilegal, puede entreverse algo aparentemente contradictorio: Si bien la Corte deniega los argumentos jurídicos de Gran Bretaña, termina basando su decisión en las pruebas ilegalmente obtenidas. Dicho de otra manera, el Tribunal rechaza las acciones militares de uno de los Estados pero condena a Albania teniendo en cuenta la evidencia ilegítimamente decomisada en tales operaciones militares $^{71}$. Fue así como la "Operación retail" proporcionó a la Corte toda la información necesaria para su fallo, entre la cual se encontraba el tipo de minas usadas, la época en la que fueron colocadas y la afectación producida por estas armas a los marinos ingleses ${ }^{72}$.

\section{iv. Excepciones a las reglas de exclusión}

Las reglas generales de exclusión anteriormente expuestas tienen las excepciones que a continuación se presentan:

\section{v. Doctrina de la necesidad}

Esta doctrina permite a los Estados sustraerse de obligaciones internacionales, entre las cuales podrían encontrarse reglas de exclusión de evidencia, con el fin de garantizar unos principios esenciales o en virtud de una necesidad nacional imperativa. El artículo 33 del "Proyecto de artículos sobre responsabilidad del Estado

69 Corte Internacional de Justicia. Caso Corfu Channel (United Kingdom of Great Britain and Northern Ireland vs. Albania). Merits. I.C. J. Reports 1949. p. 10

$70 \quad$ Ibídem. p. 33.

71 Nótese que a pesar de que la Corte rechaza el uso de la fuerza por parte de Gran Bretaña al responder la segunda pregunta de fondo, finalmente decide por 11 votos contra 5 que efectivamente ocurrieron las explosiones en el mar de Albania y que ese Estado era responsable por ellas. Ver : Corte Internacional de Justicia. Caso Corfu Channel (United Kingdom of Great Britain and Northern Ireland vs. Albania). Merits. I.C. J. Reports 1949. pp. 32-36.

72 Ibídem. 
por hechos internacionalmente ilícitos ${ }^{\prime 3}$ adoptado por la Comisión de Derecho Internacional y señalado a la atención de los gobiernos por la Asamblea General de Naciones Unidas, ${ }^{74}$ contiene los límites de la doctrina. La citada norma dispone que un Estado no puede invocar la doctrina del estado de necesidad a menos que el acto ilegal sea el único método para proteger intereses esenciales de la nación o el acto ilegal no cause daño a intereses esenciales de Estados extranjeros. Adicionalmente, el estado de necesidad no podrá invocarse si se trata de violar una norma no perentoria de derecho internacional o si el tratado que incluye la obligación internacional impide explícitamente el uso de la doctrina de necesidad. Esta excepción tampoco podrá invocarse si el Estado que la alega ha contribuido a la ocurrencia de dicha situación.

Actualmente en Derecho Internacional sólo existe una excepción a la regla de exclusión de la tortura y es usar la evidencia en contra de la persona que la cometió y en un caso que verse sobre tal prohibición. No obstante, en sistemas nacionales el tema ha sido tratado de forma diferente. La Corte Suprema de los Estados Unidos ha establecido que la regla de exclusión podría ceder si la introducción de la evidencia puede aportar a la verdad o significativamente aportar a la función del juicio penal y siempre y cuando el apoyo a la conducta ilegítima de la policía sea meramente especulativo ${ }^{75}$.

\section{vi. Derecho de "auto-protección" o de acciones unilaterales}

Este principio de Derecho Internacional, a pesar de no tener aceptación por parte de la comunidad internacional, fue alegado por el gobierno de Gran Bretaña como justificación para su irrupción en territorio Albanés en el caso del canal de Corfú ${ }^{76}$. Guarda una estrecha relación con otras excepciones a la violación de normas de Derecho Internacional que se dan en contextos de obtención irregular de evidencia.

El derecho de "auto-protección" se define en este contexto, como la posibilidad que tiene un Estado de tomar medidas frente a una infracción grave de Derecho Internacional y de esta manera obtener evidencia del Estado infractor mediante acciones que bajo condiciones normales serían vistas como violaciones a los derechos del otro Estado ${ }^{77}$. Es necesario mencionar que la Corte Internacional de Justicia rechazó el argumento del gobierno de Gran Bretaña, en el sentido en el que consideró que las intervenciones para obtener evidencia de la contraparte eran de

73 Proyecto de Artículos sobre responsabilidad del Estado por hechos internacionalmente ilícitos. 53 UN GAOR Supp. (No. 10) at 43, U.N. Doc. A/56/10 (2001).

74 Responsabilidad del Estado por hechos internacionalmente ilícitos. General Assembly Resolution, A/Res/56/83 (2002/01/28)

75 Estados Unidos. Corte Suprema. EB. James vs. Illinois, 493 U.S. 307, 311 (1990).

76 Corte Internacional de Justicia. Caso Corfu Channel. Op. cit. p. 35.

77 Ibídem. 
hecho violaciones al Derecho Internacional injustificadas y que habían dado paso a graves irrupciones a la soberanía de los Estados ${ }^{78}$.

La Corte reconoció lo extenuante que podía llegar a ser solicitar por medios diplomáticos la evidencia en cabeza del gobierno Albanés, pero expresó que tales dilaciones no eran razón suficiente para entrar al territorio de ese Estado ${ }^{79}$. De la misma manera algunos comentadores del caso han evidenciado otros problemas que surgen de las acciones de Gran Bretaña: no sólo las irrupciones en la soberanía podrían justificarse con base en las complicaciones diplomáticas para obtener la evidencia, sino que este tipo de intervenciones convertirían al demandante de un caso, en fiscal o ente acusador ${ }^{80}$.

En la situación hasta el momento presentada y en todo caso, se debe considerar que cualquier Estado que aduce una evidencia debe llevarla para presentación a la Corte que ipso facto la examinará y determinará su jurisdicción sobre la base del acto ocurrido ${ }^{81}$.

\section{vii. Reglas de exclusión de cada Corte o Tribunal en litigios de Derechos Humanos o Derecho Internacional Humanitario}

El análisis de las distintas representaciones de ilegalidad revela resultados desconcertantes, ya que a pesar de existir un relativo consenso entre los operadores del Sistema al considerar estas trasgresiones como actos reprochables, no todas las Cortes inadmiten la evidencia obtenida ilegalmente. No obstante, y como se señaló anteriormente, todas las decisiones de las Cortes sobre admisibilidad de estas pruebas encuentran asidero en la lógica del Sistema, en especial cuando se trata de litigios originados en la supuesta vulneración de los Derechos Humanos o del Derecho Internacional Humanitario. Por esta razón, se hace necesario reseñar brevemente los casos emblemáticos de pruebas obtenidas ilegalmente, acompañados de las decisiones de los Tribunales sobre admisibilidad o inadmisibilidad de ciertos medios probatorios.

\section{viii. Corte Penal Internacional}

La Corte Penal Internacional (en adelante CPI o Corte) fue fundada bajo el Estatuto de Roma, con el fin de perseguir a quienes cometieren delitos de revestida importancia en el Derecho Internacional. Para apreciar la regla de admisibilidad de las pruebas ilegal o ilícitamente obtenidas establecida para las actuaciones de la Corte, debemos referirnos específicamente al artículo 69 del Estatuto de Roma. Dicho

\footnotetext{
$78 \quad$ Ibídem

79 Ibídem.

80 HASAN SHAH, Nasim. Op. cit. p. 601.

81 THIRLWEY, Hugh. Op. cit. p. 638.
} 
artículo titulado Práctica de Pruebas, por un lado, en su numeral tercero establece que las partes podrán presentar pruebas pertinentes y que el adjudicador podrá pedir pruebas de manera oficiosa. Por otra parte, en su numeral cuarto establece la regla sobre admisibilidad:

"La Corte podrá decidir sobre la pertinencia o admisibilidad de cualquier prueba, teniendo en cuenta, entre otras cosas, su valor probatorio y cualquier perjuicio que pueda suponer para un juicio justo o para la justa evaluación del testimonio de un testigo, de conformidad con las Reglas de Procedimiento y Prueba." ${ }^{\text {P2 }}$

Adicionalmente, el numeral séptimo de la norma continúa con la enumeración de los criterios de exclusión de las pruebas, estableciendo que estas no serán admitidas si trasgreden el estatuto de la Corte o los derechos humanos internacionalmente reconocidos, siempre y cuando dicha violación suscite dudas sobre la veracidad de la prueba o su admisión atente contra la integridad del juicio ${ }^{83}$. En conclusión, la admisibilidad de una prueba ilegal o ilícitamente, obtenida ante la CPI será decidida en concordancia con el principio del debido proceso, del valor probatorio de la prueba y del posible impacto negativo que tenga su admisión sobre la legitimidad de la Corte. Con ello se deja entonces la puerta abierta a la argumentación que hagan los jueces para sostener su posición.

Como se pudo observar, el artículo de la referencia establece criterios no taxativos de evaluación de admisibilidad de las pruebas, tal como se verá en los otros tribunales analizados en esta sección del texto. Sin embargo, la vaguedad de tal disposición, al no limitar el estudio a un medio probatorio en particular, así como al no definir con mayor precisión el contenido sustancial de los criterios de exclusión, deja al adjudicador un amplio margen interpretativo para que decida de acuerdo con los intereses sistémicos y en últimas, a los criterios de auto-legitimación del Sistema Jurídico Internacional.

\section{ix. Corte Interamericana de Derechos Humanos}

La Corte Interamericana de Derechos Humanos (en adelante Corte IDH o Corte) está diseñada para proteger los derechos humanos en la región americana. Ninguno de los instrumentos que hacen parte del Sistema Interamericano de Derechos Humanos, ${ }^{84}$ en especial la Convención Americana de Derechos Humanos (en

82 Estatuto de Roma de la Corte Penal Internacional. UN Doc. A/CONF. 183/9; 37 ILM 1002 (1998); 2187 UNTS 90

$83 \quad$ Ibídem. Artículo 69, numeral 7.

84 Nótese que los tratados que hacen parte del Sistema Interamericano no se limitan al Pacto de San José. En ese sentido, la Corte tiene competencia para pronunciarse, al menos sobre la vulneración de algunas disposiciones incluidas en el Pacto de San Salvador, en la Convención de Belem Do Pará, entre otros. 
adelante la Convención) o el Reglamento mismo de la Corte, contienen una mención explícita sobre la exclusión o admisión, durante el proceso supranacional, de pruebas obtenidas de manera ilícita.

Sin embargo, analizando el artículo 8 sobre garantías judiciales, la Corte ha llegado a la siguiente subregla interpretativa: Si con ocasión de la vulneración o delimitación arbitraria de los derechos consagrados en la Convención, se obtiene información que pueda ser categorizada como medio de prueba, se considerará prueba ilícita siempre y cuando aparte del derecho vulnerado también se afecten las garantías procesales del artículo 8. Lo anterior puede ilustrarse en el siguiente ejemplo: La Convención consagra el derecho a la integridad personal (Art. 5). Si se llega a obtener una confesión por conducto de una vulneración a la integridad personal, aún cuando la misma no constituya tortura, esta prueba será considerada ilegal por violar lo preceptuado en el artículo 8.3 de la Convención ${ }^{85}$ y consecuentemente, deberá ser inadmitida.

Ahora bien, en tratándose de la jurisprudencia de La Corte, ésta no ha sentado doctrina alguna en la que analice de manera concreta el hecho de que las partes (Víctimas o Estados) o que la Comisión Interamericana (en adelante Comisión), pretendan introducir al litigio una prueba obtenida ilegalmente ${ }^{86}$. Pese a lo anterior, la Corte sí ha hecho algunos pronunciamientos con respecto a las garantías procesales derivadas del artículo 8 de la Convención, y en dichos fallos ha llegado a consideraciones sobre la licitud de algunas pruebas en situaciones específicas como se verá a continuación:

En el caso Cantoral Benavides vs. Perú el Tribunal declaró la responsabilidad del Estado de Perú, pues la Comisión logró comprobar que dicha nación, por intermedio de sus agentes, torturó de manera física y psicológica al señor Benavides con un doble propósito: por un lado, en la fase previa a la condena, pretendía suprimir su resistencia física y mental para que así la víctima se auto incriminara, aceptando la comisión de determinadas conductas delictivas; y por otro lado, en la fase posterior a la condena, buscaba someterle a castigos adicionales a los que ya había sido condenado ${ }^{87}$.

La Corte llegó a la conclusión de que se violaba la presunción de inocencia (Art. 8.2 de la Convención) ya que la detención del individuo y el proceso no estuvo respaldado "por fundamentos razonables de incriminación"88. De igual forma el Tribunal constató la violación de otras disposiciones contenidas en el artículo 8 tales como el derecho a ser oído por un tribunal independiente e imparcial (artículo

85 ARMENTA DEU, Teresa. La Prueba Ilícita (Un estudio comparado). Segunda Edición. Madrid, España. Editorial Marcial Pons. 2011. pp. 140 -141.

$86 \quad$ Ibídem. p. 141.

87 Corte IDH. Caso Cantoral Benavides vs. Perú. Fondo. Serie C No. 69. Sentencia de 18 de Agosto de 2000.

$88 \quad$ Ibídem. párr. 116. 
8.1) a contar con medios adecuados para preparar la defensa (artículo 8.2.c), a elegir un abogado (artículo 8.2.d), a interrogar testigos (artículo 8.2.f), a no ser obligado a declarar contra sí mismo y a declarar sin coacción de naturaleza alguna (artículo 8.2.g y 8.3), non bis in idem (artículo 8.4) y a la publicidad del proceso (artículo $8.5)^{89}$.

De lo anterior se puede colegir que ante esta Corte, una prueba obtenida bajo tortura debe considerarse ilícita aún en aquellos procesos que se surtan ante el respectivo Sistema Jurídico doméstico, puesto que tal evidencia estaría en clara violación de la Convención y de otros Tratados que hacen parte del Sistema Interamericano ${ }^{90}$.

Continuando con esta línea argumentativa, la Corte en el caso Tibi vs. Ecuador demostró que el señor Daniel Tibi fue sometido a tortura por parte de agentes estatales ecuatorianos, violando su derecho a la integridad personal ${ }^{91}$. Los hechos considerados tortura se cometieron con el propósito de que Tibi se declarara culpable de determinadas conductas delictivas de las que se le estaba, supuestamente, investigando $\mathrm{o}^{92}$. La Corte determinó que las garantías procesales consagradas en el artículo 8.2 y 8.3 de la Convención se deben respetar también en procedimientos anteriores o simultáneos a los procesos judiciales y que, en caso de ser vulneradas, tal trasgresión puede tener un efecto adverso en la situación jurídica del procesado ${ }^{93}$.

En la sentencia de fondo, reparaciones y costas del caso de los hermanos Gómez Paquiyauri vs Perú, la Corte admitió el video remitido por la representante de las presuntas víctimas y sus familiares el $1^{\text {o }}$ de mayo de $2004^{94}$. No obstante, no le da a la respectiva pieza documental carácter de plena prueba, sino que aprecia su contenido dentro del contexto del acervo probatorio y aplicando las reglas de la sana crítica" ${ }^{\prime 2}$.

Interesante es lo que se consideró en el fallo precitado, pues el Tribunal declaró que pese a que una de las partes había aportado una prueba viciada con irregularidades, tales como que estaba en blanco y negro y no podía categorizarse debidamente ${ }^{96}$, esta debía admitirse bajo el entendido de que no se pueden sacrificar los

$89 \quad$ Ibídem. párr. 198.

90 Nótese que en el caso Cantoral Benavides vs. Perú la Corte no sólo encuentra una vulneración de algunas disposiciones de la Convención sino de los artículos 2, 6 y 8 de la Convención Interamericana para Prevenir y Sancionar la Tortura. Ver: Ibídem. párr. 198, numeral 11.

91 Corte IDH. Caso Tibi vs. Ecuador. Serie C No. 114. Sentencia de 7 de Septiembre de 2004. párr. 142 a 163.

$92 \quad$ Ibídem. párr. 149.

$93 \quad$ Ibídem. párr. 164 a 200.

94 Corte IDH. Caso Hermanos Gómez Paquiyauri vs. Perú. Serie C No.110. Sentencia de 8 de Julio de 2004. párr. 55.

95 Ibídem. párr. 56.

96 Ibídem. 
fines de la justicia por meras formalidades ${ }^{97}$, lo que enmarca la posibilidad de que en futuros casos la Corte admita pruebas irregulares bajo la misma consideración.

\section{x. Tribunal Europeo de Derechos Humanos}

El TEDH se encarga de castigar las violaciones del Convenio para la Protección de los Derechos Humanos y las Libertades Fundamentales (en adelante CEDH). En el texto del CEDH o del Reglamento del TEDH, no existe una regla de exclusión, por lo que la jurisprudencia del Tribunal se ha encargado de regular en cuáles casos la obtención de una prueba, que viole un derecho consagrado en el CEDH, debe excluirse del acerbo probatorio ${ }^{98}$. Por esta razón, a continuación presentaremos brevemente los casos hito en los que se ha tratado el tema de exclusión de la prueba.

El artículo 3 de la CEDH reza lo siguiente: "Nadie podrá ser sometido a tortura ni a penas o tratos inhumanos o degradantes". Como consecuencia de esta prohibición, no se admiten pruebas obtenidas bajo tortura, ya que las mismas conminan la violación del artículo 3. El problema se centra entonces en definir qué se considera tortura. El TEDH en el caso Jalloh vs. Alemania recopiló su jurisprudencia en la que se determina qué debe entenderse por violación del artículo 3 de la CEDH. Se considera inhumano si el trato objeto de estudio fue premeditado, se aplica de corrido y causa lesiones a la integridad física o intenso sufrimiento físico y mental ${ }^{99}$. Se ha calificado de degradante aquél trato cuyo propósito es despertar en las víctimas sentimientos de miedo, angustia e inferioridad capaces de humillar y degradarlos, rompiendo su resistencia física o moral, o cuando pretende conducir a la víctima a actuar contra su voluntad o su conciencia ${ }^{100}$.

En cuanto a la exclusión de la prueba en violación de otras disposiciones cabe resaltar que el artículo 6 de la CEDH consagra el derecho a un proceso justo. La jurisprudencia del Tribunal ha hecho particular énfasis en el derecho de contradicción de la prueba. Por ejemplo, en el caso Lüdi vs Suiza, el TEDH rechazó un testimonio anónimo, debido a que contra quien se utilizó la prueba no tuvo la posibilidad de contradecirla $^{101}$. Tal como expresa la doctrinante Armanda Deu:

97 Corte IDH. Caso Juan Humberto Sánchez. Sentencia de 26 de noviembre de 2003. Serie C No. 102, párr. 42; Caso19 Comerciantes. Sentencia de 12 de junio de 2002. Serie C No. 93, párr. 35; Caso Ivcher Bronstein. Sentencia de 6 de febrero de 2001. Serie C No. 74, párr. 67; Caso "La Última Tentación de Cristo" (Olmedo Bustos y otros). Serie C No. 73, párr. 51 y Caso hermanos Gómez Paquiyauri vs Perú. Serie C, núm. 110. Sentencia de 8 de julio de 2004, párr. 58.

98 TEDH. Caso Allan vs. Reino Unido (No. 48539/99), Sentencia del 5 de noviembre de 2002, párr. 42.

99 TEDH. Caso Jalloh vs. Alemania (No. 54810/2000), Sentencia del 11 de julio de 1006, párr. 68.

100 Ibídem.

101 TEDH. Caso Ludi vs. Suiza (No. 12433/86), Sentencia del 15 de junio de 1992, párr. 49. 
"De este modo, la validez del testimonio se subordina a que la defensa le sea posible controlar de forma efectiva la veracidad del testimonio. La validez se ha rechazado, por ejemplo, cuando por el desconocimiento del testigo y la imposibilidad de llamarlo a declarar en el juicio, el tribunal no puede alcanzar la necesaria convicción sobre su credibilidad"102.

Así las cosas, para determinar la vulneración del derecho a un proceso justo es importante tener presente que este derecho mira el proceso como una unidad, por lo que no debe subestimarse el peso que tuvo la prueba ilícita en la condena del procesado, en relación con el resto del material probatorio. Tal como el TEDH aseguró en el caso Schenk vs. Suiza, no toda irregularidad viola el derecho al proceso justo, ya que la grabación telefónica ilegal no fue la única prueba en que se basó su condena el tribunal doméstico suizo ${ }^{103}$.

Por otro lado, cuando la exclusión de la prueba implica la violación del derecho a la vida privada, familiar, de domicilio y correspondencia, el artículo 8 del CEDH dispone que cualquier tipo de injerencia en estas esferas tiene que estar sometida a los requisitos legales y constitucionales del país miembro, siempre y cuando estos se justifiquen con alguno de los siguientes propósitos: “...sea necesaria para la seguridad nacional, la seguridad pública, el bienestar económico del país, la defensa del orden y la prevención de las infracciones penales, la protección de la salud o de la moral, o la protección de los derechos y las libertades de los demás".

El TEDH ha establecido tres etapas para la determinación de una violación del artículo 8, la cual llevaría a la eventual exclusión de la prueba que originó dicha vulneración. Primero es necesario determinar si la presunta violación cabe en el ámbito de aplicación del artículo. Después el Tribunal tiene que analizar si la presunta violación es acorde con la ley nacional. Por último, se debe estudiar si la intromisión en la esfera particular del individuo se encuentra dentro de alguna de las causales de justificación que la mencionada norma contempla. Debido a que los últimos dos pasos del test son auto referentes, bien sea desde la perspectiva del Sistema Jurídico Nacional o Internacional, únicamente desarrollaremos el contenido del primer paso ${ }^{104}$.

El artículo 8 protege a las personas para que no se interfiera en las relaciones existentes entre el individuo y sus semejantes, así como también se refiere a la protección de los datos de los ciudadanos ${ }^{105}$. El ámbito de aplicación de este artículo también depende de la expectativa de privacidad que tienen los individuos al interactuar en un espacio público o privado, excluyendo del ámbito de protección de

\footnotetext{
102 ARMENTA DEU, Teresa. Op. cit. pp. 128-129.

103 TEDH. Caso Schenk vs. Suiza (10862/84), Sentencia del 12 de julio de 1988, párr. 48.

104 TEDH. Caso P.G. y J.H. Vs. Reino Unido. (44787/98), Sentencia del 25 de septiembre de 2001. párr. 61.

105 Ibídem. párr. 57.
} 
esta norma los actos públicos. Por ejemplo, el ciudadano es consciente que si va por la calle puede ser observado por terceros y por la autoridades estatales, sin embargo, cuando se obtiene un registro de esa misma actuación pública (como cuando es grabada por un circuito cerrado de televisión) la utilización de dicho registro entra a ser cubierto por el artículo 8 del $\mathrm{CEDH}^{106}$.

\section{xi. Tribunal Penal Internacional para la antigua Yugoslavia}

El Tribunal Penal Internacional para la antigua Yugoslavia (en adelante Tribunal) fue creado por el Consejo de Seguridad de las Naciones Unidas, mediante resolución número 827 del 25 de mayo de 1993, con el fin de ejercer funciones jurisdiccionales en temas relacionados con las serias violaciones contra el Derecho Internacional Humanitario ocurridas desde el 1 de enero de 1991 en el territorio de la antigua Yugoslavia.

El Estatuto Internacional Penal para la antigua Yugoslavia (en adelante EIPY), creado con posterioridad a la guerra que cobró miles de vidas a ciudadanos de esta nación, en su artículo 15, regula el manejo de las evidencias que se desean tener en cuenta durante el desarrollo de los enjuiciamientos. Así pues, dicha norma contempla que "los jueces del Tribunal Internacional deberán adoptar leyes de procedimiento y evidencia para la realización de la fase de instrucción del procedimiento, el juicio y apelación, la admisión de pruebas, la protección de las víctimas y los testigos y a otros asuntos pertinentes" 107 .

Los jueces en este tribunal tienen la facultad de establecer las reglas sobre la admisión de pruebas. Esta facultad deóntica se rige por los principios que guían el Sistema de Derecho Internacional ${ }^{108}$. Sumado a lo anterior, los jueces, al igual que los de la Corte Penal Internacional, tienen un amplio margen de autonomía hermenéutica, toda vez que el EIPY no define de manera expresa un límite sustancial para la admisión de pruebas, recurriendo al igual que en la función anterior, a los criterios establecidos en otras cortes internacionales.

En desarrollo de la regla 15 del EIPY el Tribunal profirió la Resolución sobre Reglas de Procedimiento y Evidencia (en adelante RPE) adoptadas el 11 de febrero de 1994. Las RPE en su articulado regulan el manejo de la evidencia dentro de los procesos llevados por el tribunal.

106 Ibídem. párr. 61.

107 Estatuto del Tribunal Penal Internacional para la Ex Yugoslavia. Artículo 15. SC res. 827, UN SCOR 48th sess., 3217th mtg. at 1-2 (1993); 32 ILM 1159 (1993).

108 Las reglas de esta Corte emergieron tras una álgida discusión legal, de la cual hicieron parte los jueces miembros del Tribunal para el año de 1994, miembros de la oficina para asuntos legales de las Naciones Unidas, al igual que varios Estados y ONGs. 
El literal c del artículo 89 de las RPE, señala que deberá ser admitida por el Tribunal cualquier evidencia relevante que tenga un valor probatorio ${ }^{109}$. El amplio margen de admisibilidad que este literal supone se encuentra limitado por lo dispuesto en el literal d) del mismo artículo, el cual dispone que la prueba será excluida si se evidencia que afecta la seguridad de un juicio justo ${ }^{110}$. El concepto de juicio justo en este caso es una estructura de legitimación material que al no estar normativamente definida, permite un amplio margen hermenéutico por parte de los operadores del sistema.

Adicional a estos criterios generales, las RPE en su artículo 95 consagran una regla de exclusión sobre obtención de evidencia por mecanismos contrarios a la protección internacional de los Derechos Humanos. La norma contempla que ninguna prueba deberá ser admitida por el Tribunal si los mecanismos que se emplearon para obtenerla generan algún tipo de daño serio a la integridad de los procedimientos que se deben adelantar ante el Tribunal o si se tienen dudas sobre su fiabilidad ${ }^{111}$.

Es preciso señalar que esta regla no se encontraba contemplada dentro de la resolución original del año de 1994, sino que fue incorporada a las RPE el 30 de Enero de 1995, formulando así la teoría que anteriormente se expuso ${ }^{112}$. De lo hasta aquí dicho se deduce sin lugar a duda, que si bien las RPE del Tribunal para la antigua Yugoslavia detentan un carácter amplio, sobretodo en cuanto a la admisibilidad de pruebas en atención a los medios por los que se han obtenido, también es cierto que se contemplan una serie de criterios que delimitan su admisibilidad y que son usados de forma similar en otros tribunales internacionales.

\section{xii. Tribunal Penal Internacional para Ruanda}

El Tribunal Penal Internacional para Ruanda (en adelante TPIR o Tribunal) fue creado por el Consejo de Seguridad de las Naciones Unidas a petición del gobierno Ruandés, mediante resolución número 955 del 8 de noviembre de 1994, con el fin de ejercer funciones jurisdiccionales en temas relacionados con el genocidio y la

109 Se transcribe el texto en su idioma original: "A Chamber may admit any relevant evidence which it deems to have a probative value". Ver: Tribunal Penal para la Ex Yugoslavia. Reglas sobre Procedimiento y Prueba. UN Doc. IT/32/Rev.37 (2006).

110 Se transcribe el texto en su idioma original: "A Chamber may exclude evidence of its probative value is substantially outwighed by the need to ensure a fair trial".

111 Se transcribe el texto en su idioma original: "No evidence shall be admissible if obtained by methods which cast substantial doubt on its reliability or if its admission is antithetical to, and would seriously damage, the integrity of the proceedings". Tribunal Penal para la Ex Yugoslavia. Reglas sobre Procedimiento y Prueba. Op. cit.

112 El texto original de 1994 era el siguiente: "evidence obtained directly or indirectly by means which constitute a serious violation of internationally protected human rights shall not be admissible." 
ejecución de delitos de lesa humanidad en Ruanda ${ }^{113}$. El Consejo de Seguridad constituyó el Estatuto del Tribunal ${ }^{114}$ y con posterioridad se confeccionaron las reglas sobre procedimiento y evidencia con las que habría de operar. Sobre la materia objeto de estudio es indispensable referirse al artículo 95 del documento de reglas de procedimiento y evidencia, que es del siguiente tenor:

"Regla 95: Exclusión de Evidencia con base en los medios por los que fue obtenida.Ninguna evidencia será admisible si se obtiene por métodos que pongan en duda su fiabilidad o si su admisión es contradictoria, y que puedan dañar seriamente, la integridad de las actuaciones procesales"115.

Se consagra entonces una regla de exclusión expresa que hace referencia a los medios de obtención de la prueba. De forma similar a la regla consagrada para el Tribunal Penal Internacional para la antigua Yugoslavia, la norma decanta o delimita la admisibilidad de la prueba atendiendo a un criterio mucho más amplio que el de la legalidad o licitud, ya abordados para efectos del derecho interno.

De forma un tanto teleológica, el artículo plantea una regla general que debe seguir el adjudicante a la hora de valorar la admisión de la prueba, con fundamento en la fiabilidad derivada de los métodos por los que se obtiene la misma y su acoplamiento o adecuación a la integridad del proceso y a sus fines. La mencionada regla de exclusión se desenvuelve en un contexto específico propio de un tribunal Ad Hoc creado para el juzgamiento de hechos concretos como son los surgidos en el seno del genocidio ruandés. La regla de exclusión del TPIR reitera además una idea que se ha venido esbozando a través del texto, cual es la de la imposibilidad de catalogar una prueba como ilegal, atendiendo a un criterio uniforme aplicable a todo el Sistema de Derecho Internacional.

\section{xiii. Tribunal para el genocidio Camboyano}

En el año 2001, la Asamblea Nacional de Camboya, con apoyo de la comunidad internacional representada en la Organización de las Naciones Unidas, aprobó una ley que permitió la creación de una Corte que juzgaría los crímenes cometidos durante el régimen del desmantelado, para ese entonces, Khmer Rouge ${ }^{116}$.

113 Maina Peter, Chris. "The International Criminal Tribunal for Ruanda: bringing the killers to book". International Review of the Red Cross. Volumen 321. 1997. Cruz Roja Internacional. En : http://www.icrc.org/eng/resources/documents/misc/57jnz8.htm. Consultado el 10/01/2013.

114 Resolución 955 del Consejo de Seguridad (1994) sobre el establecimiento de un Tribunal Internacional para Ruanda y la adopción del Estatuto del Tribunal. SC res. 955, UN SCOR 49th sess., 3453rd mtg, U.N. Doc. S/Res/955 (1994); 33 ILM 1598 (1994).

115 Tribunal Penal Internacional para Ruanda. Reglas de Procedimiento y Evidencia. Regla 95. U.N. Doc. ITR/3/REV.1 (1995).

116 Ley sobre el establecimiento de las Salas Especiales de los Tribunales de Camboya para el enjuiciamiento de los crímenes cometidos durante el período de la Kampuchea Democrática 
Posteriormente el 29 de mayo de 2005 entraría en vigencia el acuerdo que regula la cooperación entre las Naciones Unidas y el Gobierno de Camboya para llevar a los altos dirigentes de la Kampuchea Democrática y aquellos responsables de crímenes y violaciones del Derecho Humanitario y del Derecho Penal de Camboya a juicio ${ }^{117}$. La corte encargada de esta tarea tomó el nombre de "Tribunal para el genocidio camboyano" (En adelante, Tribunal Camboyano o Tribunal).

El Tribunal, al igual que buena parte de otras cortes internacionales analizadas, cuenta con un reglamento interno que consagra normas específicas, relacionadas con el manejo del material probatorio que se emplea en los procesos ante el mismo. Con relación a la admisibilidad de pruebas, la regla 87 del documento de reglas internas del Tribunal, afirma de forma expresa que cualquier evidencia es admisible, salvo que se disponga lo contrario en el mismo reglamento ${ }^{118}$. Se puede deducir entonces de esta primera disposición que las pruebas que estén prohibidas o no se ciñan a lo dispuesto en las reglas de procedimiento del Tribunal, deben ser inadmitidas.

El Tribunal Camboyano cuenta entonces con una regla de exclusión que atiende a criterios específicos de legalidad fijados por sus propias disposiciones normativas, las cuales en realidad dicen muy poco sobre el tema en cuestión. Sin embargo, cabe señalar que la certeza sobre la admisión o exclusión de pruebas ante este Tribunal se ve someramente reforzada debido a su carácter híbrido ya que se nutre no solo del código binario del Sistema Jurídico Internacional sino también de las leyes penales del sistema doméstico ${ }^{119}$.

\section{xiv. Tribunal Especial para el Líbano}

En marzo de 2006, el Consejo de Seguridad de Naciones Unidas, considerando que aún existía demanda de justicia en el caso Al-Hariri relacionado con una explosión en Beirut que causó la muerte del referido Ministro y de trece personas más, decidió exhortar al gobierno para que negociara la creación de un tribunal internacional

(2001) (Camboya), modificada por la NS/RKM/1004/006 (27 de octubre 2004) (traducción no oficial).

117 Acuerdo entre las Naciones Unidas y el Gobierno Real de Camboya relativo al procesamiento, con arreglo al derecho de Camboya de los crímenes cometidos durante el período de la Kampuchea Democrática. 29 de abril de 2005. 2329 UNTS 117.

118 Se transcribe el texto en su idioma original: "Unless provided otherwise in these IRs, all evidence is admissible". Ver: Tribunal para el Genocidio Camboyano. Reglas Internas. Regla 87. (Octava edición del 3 de agosto de 2011). En: http://www.eccc.gov.kh/en/document/legal/ internal-rules-rev8. Consultado el 20/03/2013.

119 Ley sobre el establecimiento de las Salas Especiales de los Tribunales de Camboya para el enjuiciamiento de los crímenes cometidos durante el período de la Kampuchea Democrática. Op. cit. Artículo 1. 
$A d-H o c^{120}$. En lo que se refiere a la regla de admisión de evidencia dentro del procedimiento, el Estatuto del Tribunal en su artículo 19 estipula que la admisibilidad "deberá decidirse por las Cámaras con base en los estándares internacionales de obtención de evidencia"121. De la misma manera una vez iniciados los procedimientos "la cámara podrá admitir cualquier evidencia que considere tiene valor probatorio y excluir evidencia que cuyo valor probatorio es sustancialmente sobrepasado por la necesidad de asegurar un juicio justo" 122 (Subrayas fuera del texto original).

En caso de que no exista regla específica sobre el trato que se le debe dar a cierta prueba, "las reglas de evidencia que deberán aplicar son las que permitan realizar una determinación justa del asunto de fondo y con principios generales de Derecho Internacional"123. Según el Estatuto de Reglas de Procedimiento, los jueces deberán guiarse en temas de admisibilidad por el Código de Procedimiento Penal libanés, así como por otros materiales que positivicen los estándares más altos de procedimiento penal ${ }^{124}$.

Es así como pueden llegarse a las siguientes conclusiones sobre las reglas de admisibilidad de la prueba dentro del procedimiento especial contemplado por el Tribunal Ad-Hoc para el caso Al-Hariri. En primer lugar, no existen causales taxativas que guíen la exclusión de cierta evidencia, sino que se contempla una remisión a principios generales de derecho como garantía de un juicio justo. Adicionalmente, el Tribunal está llamado a hacer una ponderación, ya que si se encuentra una prueba presuntamente ilegal, ésta sólo será excluida si la vulneración del debido proceso supera considerablemente los beneficios derivados de la información aportada por la evidencia. La tercera y última conclusión es que el Tribunal debe integrar otros instrumentos normativos diferentes a su propio Estatuto al determinar asuntos de admisibilidad, tal y como ocurre con otros tribunales híbridos (Sistema Jurídico Internacional y Sistema Jurídico doméstico) como con el Tribunal para el genocidio camboyano.

\section{xv. Cuadro resumen de las respectivas reglas de exclusión}

El cuadro que a continuación se presenta, resume las respectivas reglas de exclusión de pruebas de los diferentes Tribunales y Cortes anteriormente analizados.

120 Solicitud para negociar un acuerdo con el Gobierno del Líbano destinado a establecer un Tribunal de Carácter Internacional. Consejo de Seguridad de las Naciones Unidas. S.C. Res. 1664, U.N. Doc. S/RES/1664 (2006).

121 Resolución para el establecimiento de un Tribunal Especial para el Líbano (Estatuto anexo). Consejo de Seguridad de las Naciones Unidas. S.C. Res. 1664, U.N. Doc. S/RES/1664 (2006). Artículo 19.

122 Ibídem. Artículo 21.

123 Ibídem.

124 Ibídem. Artículo 28.2. 


\section{Corte o Tribunal}

Corte Penal

Internacional

\section{Regla de exclusión}

Artículo 69 del Estatuto. Deja al adjudicador un amplio margen hermenéutico para que decida, de acuerdo con los intereses sistémicos del Tribunal y el valor probatorio del material presentado.

Corte Interamericana $\mathrm{Si}$ vulnerándose o limitándose arbitrariamente los de Derechos Humanos derechos consagrados en la Convención Americana, se obtiene información que pudiere ser un medio de prueba, se considerará ilícita siempre y cuando, aparte del derecho vulnerado, también se afecten las garantías procesales del artículo 8 de la Convención. El desarrollo del tema se ha continuado por vía jurisprudencial.

Tribunal Europeo de Derechos Humanos

No existe una regla de exclusión explícita, pero la jurisprudencia ha regulado en cuáles casos la obtención de una prueba que viole un derecho consagrado en el $\mathrm{CEDH}$, debe excluirse del acerbo probatorio.

Tribunal Penal Artículo 95 del Estatuto. Los jueces tienen una amplia Internacional para la autonomía interpretativa, limitada por ciertos criterios Antigua Yugoslavia de admisibilidad usados en otros tribunales.

Tribunal Penal El artículo 95 de las reglas de procedimiento específicaInternacional para Ruanda mente dispone que no se admitirá la evidencia obtenida por medios que pongan en duda su fiabilidad o que puedan vulnerar considerablemente la integridad del proceso.

Tribunal para Artículo 61 de las reglas de procedimiento de forma el Genocidio Camboyano expresa ha definido que cualquier evidencia es admisible, salvo que se disponga lo contrario en el mismo reglamento. En todo caso deberá tomarse en cuenta la ley penal doméstica de Camboya.

Tribunal Especial para el Líbano
$\mathrm{El}$ adjudicador debe remitirse a los principios generales de derecho como la garantía de un juicio justo. En los casos en que encuentre una prueba presuntamente ilegal, sólo la excluirá si la vulneración del debido proceso sobrepasa considerablemente los beneficios derivados de la información aportada por la evidencia. El Tribunal debe integrar otros instrumentos normativos diferentes a su propio Estatuto, como la ley doméstica, al determinar asuntos de admisibilidad. 


\section{CONCLUSIONES Y PROPUESTAS SOBRE LAS REgLAS DE EXCLUSIÓN EN EL DERECHO INTERNACIONAL}

Habiendo realizado un análisis sistemático del Derecho Internacional, entendido como un sistema con principios y fines propios que impregnan y permean todas las partes que lo componen, sus operadores y los sujetos sobre los cuales recaen sus operaciones, es posible derivar varias conclusiones con relación al manejo que en términos de admisibilidad e inadmisibilidad se hace de las pruebas. Centramos nuestro estudio en aquella evidencia cuya obtención y práctica se efectúa a través de medios ilegales o ilícitos, desde la regulación existente, su tratamiento en diferentes tribunales y los aportes que sistemas domésticos como el colombiano pueden realizar al Sistema de Derecho Internacional.

En cuanto a la regulación analizada sobre el tema, es preciso destacar el papel que juegan las reglas de exclusión de cada tribunal al ser los principales cuerpos normativos sobre el tratamiento del material probatorio obtenido ilegalmente. Estas reglas obran como una estructura de legitimación del Sistema más allá de cada corte o tribunal. Su consagración materializa los fines del Sistema de Derecho Internacional y concretamente, del DDHH y del DIH, que se ha encargado de estatuir dichos tribunales, los cuales como operadores y a razón de los poderes deónticos que poseen, son los encargados de desarrollar los fines sistémicos, cuales son lograr una recta impartición de justicia incluso si ello comporta la sanción de agentes estatales.

Criterios como la justicia o la integridad de los procedimientos, usados en cada corte o tribunal para determinar la admisión del material probatorio, además de ser herramientas de auto legitimación material, son también un ejemplo de la coherencia y del carácter teleológico del Sistema de Derecho Internacional. Sus fines se manifiestan en cada regla de exclusión, guiando a todos los operadores hacia el cumplimiento, no de una regla en particular, sino de todas las comunicaciones permitidas por él mismo.

No obstante, las normas que contemplan dichos criterios de exclusión de evidencias obtenidas ilegalmente, en el ámbito del Derecho Internacional y en la esfera de cada corte, se muestran en extremo vagas. Esto quiere decir, que las comunicaciones del Sistema, a pesar de cumplir su función, lo hacen de manera superficial, lo cual indica que el desarrollo sustancial de los criterios de exclusión tiene un amplio margen de discrecionalidad hermenéutica. Resultan pues poco técnicos y mantienen un estado de indefinición respecto de qué pruebas deben inadmitirse en virtud de los medios por los cuales fueron obtenidas. Este es un problema sistémico, ya que se encuentra en todos los niveles de análisis del Sistema Jurídico de Derecho Internacional (a nivel de principios generales del Derecho Internacional, en las reglas de los tribunales ad hoc y en los tribunales permanentes). 
En relación con los principios generales de Derecho Internacional aplicables a la admisibilidad de pruebas obtenidas ilegalmente, la claridad que se tiene sobre las consecuencias de su violación también es reducida. Por ejemplo, en cuanto al principio de no intervención estatal y respeto a la soberanía, no es uniforme la consecuencia jurídica sobre la exclusión de la prueba. En el caso del Canal de Corfú, a pesar de haberse reconocido una violación al derecho sustancial, la ausencia de una sanción radical para dicha violación muestra la vaguedad del Sistema en el tratamiento de la prueba. Así mismo, en el Tribunal de Ruanda se hace referencia a la integridad de los procedimientos para determinar la admisión de material probatorio, sin definir qué se debe entender por integridad de los procedimientos o qué actuaciones pueden afectarla.

Dicha falla sistémica ha conllevado a que la protección de los fines del Sistema Jurídico Internacional no pueda cumplirse a cabalidad. Esto gracias a que los adjudicadores, al momento de desarrollar los criterios de exclusión de la prueba, pueden producir comunicaciones erráticas llegando a afectar la coherencia del Sistema. Es menester entonces que el Sistema evolucione ${ }^{125}$, reduciendo los grados de libertad (margen de interpretación) que tiene el operador a la hora de determinar la admisibilidad de pruebas obtenidas ilegalmente, logrando así un mayor control sobre las comunicaciones. Dicha tarea podría ser realizada por la Comisión de Derecho Internacional, ya que ésta posee el poder deóntico que la faculta para recopilar jurisprudencia y desarrollar el Derecho Internacional Público ${ }^{126}$. También podría darse al interior de los mismos tribunales al dictar sus reglas de procedimiento y evidencia.

Para la correcta reducción de los grados de libertad, el Derecho procesal juega un rol de vital importancia, ya que dicha disciplina jurídica permea de manera transversal las demás ramas del Derecho y ha determinado los contenidos de muchos de los criterios utilizados en el Sistema de Derecho Internacional. Por ejemplo, con el fin de diferenciar la consecuencia probatoria procesal de la vulneración de normas de Ius Cogens de aquellas no perentorias, el Sistema de Derecho Internacional puede tomar como guía la diferenciación entre prueba ilícita e ilegal que se hace en el Sistema Jurídico colombiano. Lo anterior con la salvedad ya estipulada en los acápites anteriores sobre las diferencias existentes entre los sistemas domésticos e internacionales, en especial en cuanto a operadores sistémicos se refiere.

En lo que concierne al aporte que se hace desde el derecho colombiano, este debe ser visto con sigilo, ya que pese a que puede coincidir con los lineamientos de

\footnotetext{
125 La evolución del sistema se puede plasmar en el desarrollo de un "draft article" por parte de la Comisión de Derecho Internacional sobre la exclusión de pruebas ilícitas en el Derecho Internacional.

126 "El objetivo de la Comisión debe ser fomentar el desarrollo progresivo del Derecho Internacional y su codificación". Estatuto de la Comisión de Derecho Internacional. GA Resolution 174 (II). Artículo 1.1.
} 
algunos tribunales ( $v$. gr. Corte de Derechos Humanos), también encuentra diferencias con otros de los tribunales ( $v$. gr. Tribunales penales $A d H o c)$. Así pues, a diferencia de lo que sucedió en el ordenamiento jurídico colombiano, en donde la Corte Suprema de Justicia decidió inadmitir las pruebas del caso contra Wilson Borja, las Cortes penales internaciones no considerarían que tal evidencia debiera ser excluida, ya que serían más proclives a admitir elementos que pudieran resultar en una condena por grave vulneración al Derecho Internacional Humanitario.

Concluimos afirmando que el Sistema Jurídico Internacional presenta incoherencias que pueden ser solucionadas por él mismo, gracias a su carácter autopoiético. Sostenemos que en esta labor puede tomar elementos de los sistemas domésticos y evitar los criterios dispares en materia de admisión o inadmisión de pruebas, de manera que se forjen estándares uniformes en este asunto que sean precisos conceptualmente y desarrollen la anhelada seguridad jurídica. Por esta vía se estaría más cerca de una justicia globalizada, pues al tener conceptos claros es más plausible que diferentes Estados prevean las decisiones de tribunales internacionales y propendan por la legitimación del Sistema. Dicho todo lo anterior, entendemos sustentada la hipótesis de que en el Derecho Procesal Internacional hay aún vacíos en lo relacionado con la admisibilidad de las pruebas ilegalmente obtenidas. A futuros procesalistas internacionales les corresponderá un nuevo estudio sobre el tema, con el fin de determinar si el Sistema de Derecho Internacional ha llenado las lagunas que esta investigación ha puesto de presente.

\section{REFERENCIAS}

\section{Doctrina}

ARMENTA DEU, Teresa. La Prueba Ilícita (Un estudio comparado). Segunda Edición. Madrid, España. Editorial Marcial Pons. 2011.

CHINKIN, C.M. "The Challenge of Soft law: Development and change in International Law", International and Comparative Law Quarterly. Volumen 38. 1989. Londres. British Institute of International and Comparative Law. pp 850866.

DEVIS ECHANDIA, Hernando. Teoría general del proceso. Tercera Edición. Buenos Aires, Argentina. Editorial Universidad. 2004.

GÓMEZ JARA DIEZ, Carlos (coordinador). Teoría de sistemas y derecho penal. Fundamentos y posibilidades de aplicación. Primera Edición. Bogotá. Universidad Externado de Colombia. 2009.

HASAN SHAH, Nasim. "Discovery by Intervention: The Right of a State to Seize Evidence Located within the Territory of the Respondent State*. The American Journal of International Law, Volumen. 53. 1959. American Society of International Law Stable. En: http://www.jstor.org/stable/2195390. Consultado el $18 / 10 / 2012$. 
MAINA PETER, Chris. "The International Criminal Tribunal for Ruanda: bringing the killers to book". International Review of the Red Cross. Volumen 321. 1997. Cruz Roja Internacional. En: http://www.icrc.org/eng/resources/documents/ misc/57jnz8.htm. Consultado el 10/01/2013.

QUIJANO PARRA, Jairo. Manual de Derecho Probatorio. 17º edición. Bogotá, Librería Ediciones del Profesional Ltda. 2009.

REISMAN, W, Michael and FREEDMAN, Eric E. "The plaintiff's Dilemma: Illegally Obtained Evidence and Admissibility in International Adjudication", Yale Law School Legal Scholarship Series. 76 Am. J. Int'l L. 737. 1982. En:http://heinonline.org/. Consultado el 10/02/2013.

SEARLE, John. The Construction of Social Reality. Primera Edición. Nueva York. The Free Press. 1995.

SHARF, Michael. "Tainted Provenance: When, If Ever, Should Torture Evidence be admissible?" Washington and Lee Law Review. Volumen. 129. 2008. Lexington. Washington and Lee University School of Law.

THIRLWEY, Hugh. "Dilemma or Chimera? Admissibility of Illegally Obtained Evidence in International Adjudication". The American Journal of International Law, Volumen 78. 1984. Washington D.C. American Society of International Law.

\section{Jurisprudencia nacional}

Corte Constitucional, Sentencia C-491 del 2 de noviembre de 1995. M.P Antonio Barrera Carbonell. Expediente D-884.

Corte Constitucional, Sentencia C-591/05. 9 de junio de 2005. M.P Clara Inés Vargas Hernández. Expediente D-5415.

Corte Suprema de Justicia, Sala de Casación Penal, Sentencia de casación del 2 de marzo de 2005. M.P Edgar Lombana Trujillo. Proceso No. 18.103.

Corte Suprema de Justicia. Sala penal. Sentencia de Casación del 5 de Octubre de 2006. M.P Javier Zapata Ortiz. Proceso No 23284.

Corte Suprema de Justicia. Sala Civil y Agraria, Sentencia de Casación No. del 28 de abril de 2008. M.P Pedro Octavio Mudar Cadena. Expediente No. 110010203 00020030009701.

Corte Suprema de Justicia. Sala penal, Sentencia de Casación del 21 de octubre de 2009. M.P Yesid Ramírez Bastidas. Proceso No. 32193.

Corte Suprema de Justicia, Sala Penal, Providencia que resuelve recurso de reposición. 1 de agosto de 2011. Expediente No. 29.877.

Corte Suprema de Justicia, Sala de Casación Penal, Auto Inhibitorio del 18 de agosto de 2011. Expediente No. 29.877. 


\section{Jurisprudencia extranjera}

Estados Unidos. Corte Suprema. Caso Nix vs. Williams, 467 U.S. 431, 443-44 (1984).

Estados Unidos. Corte Suprema. EB. James vs. Illinois, 493 U.S. 307, 311 (1990).

Estados Unidos. Corte Suprema. Boumediene vs. Bush, 553 U.S. 723 (2008).

\section{Leyes nacionales}

Constitución Política de Colombia.

Código General del Proceso (Ley 1564 de 2012).

Código de Procedimiento Civil (Decreto 1400 de 1970 y modificaciones).

Código de Procedimiento Penal (Ley 906 de 2004).

\section{Tratados y otros instrumentos jurídicos internacionales}

Proyecto de Artículos sobre responsabilidad del Estado por hechos internacionalmente ilícitos. 53 UN GAOR Supp. (No. 10) at 43, U.N. Doc. A/56/10 (2001).

Estatuto de la Corte Internacional de Justicia. 3 Bevans 1179; 59 Stat. 1031; T.S. 993; 39 AJIL Supp. 215 (1945).

Convención de Viena sobre el Derecho de los Tratados. UN Doc. A/Conf.39/27; 1155 UNTS 331; 8 ILM 679 (1969); 63 AJIL 875 (1969).

Convención Americana de Derechos Humanos. OAS Treaty Series No. 36; 1144 UNTS 123; 9 ILM 99 (1969).

Convención de Naciones Unidas contra la tortura u otros tratos crueles, inhumanos o degradantes. GA res. 39/46, annex, 39 UN GAOR Supp. (No. 51) at 197, UN Doc. A/39/51 (1984); 1465 UNTS 85.

Cuerpo de Principios para la Protección de Todas las Personas bajo cualquier forma de Detención o Encarcelamiento. GA res. 43/173, annex, 43 UN GAOR Supp. (No. 49) at 298, UN Doc. A/43/49 (1988).

Estatuto de Roma de la Corte Penal Internacional. UN Doc. A/CONF. 183/9; 37 ILM 1002 (1998); 2187 UNTS 90.

Estatuto de la Corte Interamericana de Derechos Humanos. O.A.S. Res. 448 (IX-0/79), O.A.S. Off. Rec. OEA/Ser.P/IX.0.2/80, Vol. 1-98.

Convención Interamericana para Prevenir y Sancionar la Tortura. OAS Treaty Series No. 67; reprinted in Basic Documents Pertaining to Human Rights in the Inter-American System, OAS/Ser.L/V/I.4 Rev. 9 (2003).

Convención Europea de Derechos Humanos. ETS 5; 213 UNTS 221.

Protocolo $\mathrm{N}^{\circ} 11$ al Convenio Europeo para la Protección de los Derechos Humanos y de las Libertades Fundamentales. ETS 155. 
Convenio Europeo para la Prevención de la Tortura y los Tratos o Penas Inhumanos o Degradantes. ETS 126.

Estatuto del Tribunal Penal Internacional para la Ex Yugoslavia. SC res. 827, UN SCOR 48th sess., 3217th mtg. at 1-2 (1993); 32 ILM 1159 (1993).

Tribunal Penal para la Ex Yugoslavia. Reglas sobre Procedimiento y Prueba. UN Doc. IT/32/Rev.37 (2006).

Tratado entre Naciones Unidas y el gobierno de Sierra Leona para Establecer un Tribunal Especial (con Estatuto), Sierra Leona-O.N.U., Enero. 16, 2002, 2178 U.N.T.S. 137.

Resolución 955 del Consejo de Seguridad (1994) sobre el establecimiento de un Tribunal Internacional para Ruanda y la adopción del Estatuto del Tribunal. SC res. 955, UN SCOR 49th sess., 3453rd mtg, U.N. Doc. S/Res/955 (1994); 33 ILM 1598 (1994).

Tribunal Penal Internacional para Ruanda. Reglas de Procedimiento y Evidencia. U.N. Doc. ITR/3/REV.1 (1995).

Ley sobre el establecimiento de las Salas Especiales de los Tribunales de Camboya para el enjuiciamiento de los crímenes cometidos durante el período de la Kampuchea Democrática (2001) (Camboya), modificada por la NS/RKM/1004/006 (27 de octubre 2004) (traducción no oficial).

Acuerdo entre las Naciones Unidas y el Gobierno Real de Camboya relativo al procesamiento, con arreglo al Derecho de Camboya de los crímenes cometidos durante el período de la Kampuchea Democrática. 29 de abril de 2005. 2329 UNTS 117.

Tribunal para el Genocidio Camboyano. Reglas Internas. Regla 87. (Octava edición del 3 de agosto de 2011). En: http://www.eccc.gov.kh/en/document/legal/ internal-rules-rev8. Consultado el 20/03/2013

Solicitud para negociar un acuerdo con el Gobierno del Líbano destinado a establecer un Tribunal de Carácter Internacional. Consejo de Seguridad de las Naciones Unidas. S.C. Res. 1664, U.N. Doc. S/RES/1664 (2006).

Resolución para el establecimiento de un Tribunal Especial para el Líbano (Estatuto anexo). Consejo de Seguridad de las Naciones Unidas. S.C. Res. 1664, U.N. Doc. S/RES/1664 (2006).

Estatuto del Tribunal Especial para Sierra Leona. 2178 UNTS 138, 145; 97 AJIL 295; UN Doc. S/2002/246, appendix II.

O.N.U. Administración Transicional en Timor Oriental. Reglamento No. 2000/30 Sobre Normas Transicionales de Procedimiento Penal. UNTAET/ Reg/2000/30. párr. 34.2.

O.N.U. Consejo Económico y Social, Comisión de Derechos Humanos. Informe del relator especial Peter Kooijmans, Reporte sobre "Derechos Humanos de todas las personas sometidas a cualquier forma de detención o prisión y en particular: 
la tortura y otros tratos o penas crueles, inhumanas o degradantes", U.N. Doc, E/ CN.4/1993/26 (Dic. 15, 1992) (En la Sesión 49 de la Comisión de Derechos Humanos).

Estatuto de la Comisión de Derecho Internacional. Asamblea General de Naciones Unidas. GA Resolution 174 (II).

\section{Jurisprudencia internacional}

Corte IDH. Caso Velásquez Rodríguez. Sentencia de 29 de julio de 1988. Serie C No. 4.

Corte IDH. Caso Godínez Cruz. Sentencia de 20 de enero de 1989. Serie C No. 5.

Corte IDH. Caso Gangaram Panday. Sentencia de 21 de enero de 1994. Serie C No. 16.

Corte IDH. Caso Paniagua Morales y otros. Sentencia de 8 de marzo de 1998. Serie C No. 37.

Corte IDH. Caso Villagrán Morales y otros. Sentencia de 19 de noviembre de 1999. Serie C No. 63.

Corte IDH. Caso Cantoral Benavides vs. Perú. Sentencia de 18 de Agosto de 2000. Serie C No. 69.

Corte IDH. Caso "La Última Tentación de Cristo" (Olmedo Bustos y otros). Sentencia de 5 de febrero de 2001. Serie C No. 73.

Corte IDH. Caso Ivcher Bronstein. Sentencia de 6 de febrero de 2001. Serie C No. 74.

Corte IDH. Caso19 Comerciantes. Sentencia de 12 de junio de 2002. Serie C No. 93.

Corte IDH. Caso Juan Humberto Sánchez. Sentencia de 26 de noviembre de 2003. Serie C No. 102.

Corte IDH. Caso hermanos Gómez Paquiyauri vs Perú. Sentencia de 8 de Julio de 2004. Serie C No. 110.

Corte IDH. Caso Gudiel Álvarez y otros ("Diario Militar") Vs. Guatemala. Sentencia de 20 noviembre de 2012. Serie C No. 253.

Corte IDH. Caso Mohamed Vs. Argentina. Sentencia de 23 noviembre de 2012 Serie C No. 255.

TEDH. Caso Schenk vs. Suiza, (10862/84), Sentencia del 12 de julio de 1988.

TEDH. Caso Ludi Vs. Suiza, (No. 12433/86), Sentencia del 15 de junio de 1992.

TEDH. Caso P.G. y J.H. Vs. Reino Unido. (44787/98), Sentencia del 25 de septiembre de 2001.

TEDH., Caso Allan Vs. Reino Unido, (No. 48539/99), Sentencia del 5 de noviembre de 2002.

TEDH. Caso Jalloh Vs. Alemania, (No. 54810/2000), Sentencia del 11 de julio de 2006. 